\title{
Evaluating Mesoscale Simulations of the Coastal Flow Using Lidar Measurements
}

\author{
Floors, Rogier Ralph; Hahmann, Andrea N.; Pena Diaz, Alfredo
}

Published in:

Journal of Geophysical Research: Atmospheres

Link to article, DOI:

10.1002/2017JD027504

Publication date:

2018

Document Version

Publisher's PDF, also known as Version of record

Link back to DTU Orbit

Citation $(A P A)$ :

Floors, R. R., Hahmann, A. N., \& Pena Diaz, A. (2018). Evaluating Mesoscale Simulations of the Coastal Flow Using Lidar Measurements. Journal of Geophysical Research: Atmospheres, 123(5), 2718-2736.

https://doi.org/10.1002/2017JD027504

\section{General rights}

Copyright and moral rights for the publications made accessible in the public portal are retained by the authors and/or other copyright owners and it is a condition of accessing publications that users recognise and abide by the legal requirements associated with these rights.

- Users may download and print one copy of any publication from the public portal for the purpose of private study or research.

- You may not further distribute the material or use it for any profit-making activity or commercial gain

- You may freely distribute the URL identifying the publication in the public portal

If you believe that this document breaches copyright please contact us providing details, and we will remove access to the work immediately and investigate your claim 


\section{Journal of Geophysical Research: Atmospheres}

\section{RESEARCH ARTICLE \\ 10.1002/2017JD027504 \\ Evaluating Mesoscale Simulations of the Coastal Flow Using Lidar Measurements}

\begin{abstract}
Key Points:
- The sensitivity of simulated winds

from the WRF model to varying boundary layer schemes, boundary conditions, and horizontal resolution is studied

- The flow in a transect across the coast is evaluated using lidar measurements for the first time

- The modeling choices that have to be made to simulate the flow in the coastal zone during a 3 month period are described
\end{abstract}

\section{Supporting Information:}

- Supporting Information S1

Correspondence to:

R. Floors,

rofl@dtu.dk

\section{Citation:}

Floors, R., Hahmann, A. N., \& Peña, A. (2018). Evaluating mesoscale simulations of the coastal flow using lidar measurements. Journal of Geophysical Research: Atmospheres, 123, 2718-2736. https://doi.org/10.1002/2017JD027504

Received 26 JUL 2017 Accepted 8 FEB 2018 Accepted article online 14 FEB 2018 Published online 13 MAR 2018

○2018. American Geophysical Union. All Rights Reserved.

\author{
R. Floors' ${ }^{1}$, A. N. Hahmann' ${ }^{1}$, and A. Peña1 \\ ${ }^{1}$ DTU Wind Energy, Technical University of Denmark, Roskilde, Denmark
}

Abstract The atmospheric flow in the coastal zone is investigated using lidar and mast measurements and model simulations. Novel dual-Doppler scanning lidars were used to investigate the flow over a $7 \mathrm{~km}$ transect across the coast, and vertically profiling lidars were used to study the vertical wind profile at offshore and onshore positions. The Weather, Research and Forecasting model is set up in 12 different configurations using 2 planetary boundary layer schemes, 3 horizontal grid spacings and varied sources of land use, and initial and lower boundary conditions. All model simulations describe the observed mean wind profile well at different onshore and offshore locations from the surface up to $500 \mathrm{~m}$. The simulated mean horizontal wind speed gradient across the shoreline is close to that observed, although all simulations show wind speeds that are slightly higher than those observed. Inland at the lowest observed height, the model has the largest deviations compared to the observations. Taylor diagrams show that using ERA-Interim data as boundary conditions improves the model skill scores. Simulations with 0.5 and $1 \mathrm{~km}$ horizontal grid spacing show poorer model performance compared to those with a $2 \mathrm{~km}$ spacing, partially because smaller resolved wave lengths degrade standard error metrics. Modeled and observed velocity spectra were compared and showed that simulations with the finest horizontal grid spacing resolved more high-frequency atmospheric motion.

Plain Language Summary There is strong interest in accurate estimation of the wind resource for wind farms that are located in the coastal zone. These areas have high wind speeds for onshore flow conditions and grid connectivity is relatively easy. The atmospheric flow in the coastal zone is investigated using weather model simulations and a relatively new device (a scanning wind lidar) that can measure the wind speed using a laser beam. The weather model is set up in 12 different configurations, with varying parametrization schemes and boundary conditions. All model simulations describe the observed mean wind profile well at different onshore and offshore locations. The simulated mean horizontal wind speed gradient across the shoreline is close to that observed, although all simulations show wind speeds that are slightly higher than those observed. Inland at the lowest observed height, the model has the largest deviations compared to the observations. Simulations with the finest horizontal grid show poorer model performance, whereas using boundary conditions from the European Centre gives a better model performance. Although having a negative impact on standard performance metrics, simulations with the finest horizontal grid spacing resolved more atmospheric motion.

\section{Introduction}

There is strong interest in accurate estimation of the wind resource for wind farms that are located in the coastal zone. These areas, defined here as approximately within $10 \mathrm{~km}$ of the coastline, have high wind speeds for onshore flow conditions. Furthermore, grid connectivity is relatively easy compared to far-offshore projects. Internal boundary layers develop at the coastline due to the changes in surface conditions, which have been studied for decades (Garratt, 1990). For offshore flow conditions, Barthelmie et al. (2007) showed that the flow at a distance less than $20 \mathrm{~km}$ from the coastline is not in equilibrium with the new surface conditions and to capture the transition, a model is required.

Due to increasing computing power, it has become popular to use the output from mesoscale models to determine the wind resource (Dvorak et al., 2009; Frank et al., 2001; Tammelin et al., 2013). Mesoscale models are particularly useful for offshore wind resource estimation, due to the absence of complex and unresolved microscale features (Hahmann et al., 2015; Wijnant et al., 2014). At a measurement platform in the North Sea 
with a $106 \mathrm{~m}$ high meteorological mast (FINO3), an intercomparison of 26 model simulations showed a mean bias of less than $0.25 \mathrm{~m} \mathrm{~s}^{-1}$ at $90 \mathrm{~m}$ (Olsen et al., 2017). Near the coast, mesoscale models have difficulties in correctly simulating the atmospheric flow due to the influence of surface roughness changes (Floors et al., 2013), coastal low-level jets (LLJs) (Hunt et al., 2004), and wave-atmosphere interactions (Lange et al., 2004).

The Weather Research and Forecasting (WRF) mesoscale model is frequently used to simulate mesoscale flows (Skamarock et al., 2008). Dörenkämper et al. (2015) used WRF model simulations with a horizontal grid spacing of $700 \mathrm{~m}$ to show that streaks of lower wind speed, resulting from patches of land with higher surface roughness, can extent several tens of kilometers from the coast during offshore flow. Floors et al. (2013) used the WRF model to investigate the impact of vertical resolution and found that it had a negligible impact on the wind profile at one of the locations that is evaluated in the current study. Nocturnal LLJs were observed for easterly winds, resulting from cooling of the surface and decoupling of the flow. For westerly winds, the model strongly underestimated the wind speed, which raised the question whether mesoscale models can accurately simulate the flow in the coastal zone.

Both Floors et al. (2013) and Dörenkämper et al. (2015) used sea surface temperature (SST) data with a rather coarse resolution of $1^{\circ}$. This could influence the coastal flow, because strong gradients in SST near the coast will not be resolved in these model setups. Floors et al. (2013) furthermore showed that there were large differences in mean wind speed between simulations forced with different atmospheric boundary conditions. Nunalee and Basu (2014) also investigated the impact of using atmospheric boundary conditions from two different sources and found large differences in the ability of the WRF model to represent LLJs.

The above findings show that a correct description of all boundary conditions is necessary to simulate the flow in the coastal zone. The impact of changing the model grid spacing, the description of SST, land cover, and atmospheric boundary conditions on the simulated wind speed in the coastal zone for an extended period has not been described extensively in literature. Here we investigate such impacts by using two types of land cover data, two sources of SSTs, and two sources of atmospheric (re)analysis data.

The large changes in surface roughness and stability and the resulting internal boundary layers are often not resolved at grid spacings of $\approx 1 \mathrm{~km}$ of the current generation of mesoscale models. Still, Planetary Boundary Layer (PBL) schemes are increasingly being used at very high resolutions, where turbulent motions are partially resolved (Shin \& Dudhia, 2016). With the increase in computer power, this trend will continue. To understand better the behavior of the WRF model and the different PBL schemes at these high resolutions, it is important that the model is evaluated against high-quality measurements that can be obtained from a meteorological mast or from wind lidars.

Wind lidars have been around for several decades now (e.g., Hall et al., 1984), and they measure the line-of-sight (LOS) velocity by computing the Doppler shift of the signal of a laser beam due to moving aerosols. They are widely used for research and industrial applications (Banta et al., 2001; Mikkelsen, 2014). They are usually configured to measure at a number of heights to retrieve the vertical profile of wind speed.

Two spatially separated scanning lidars can estimate the horizontal wind speed vector from measurements of the LOS velocity assuming a zero vertical wind speed. For example, Newsom et al. (2008) used two Doppler lidars to scan an $\approx 2 \times 2 \mathrm{~km}^{2}$ area in a plan position indicator mode at a small elevation angle to investigate turbulent structures. Hill et al. (2010) used two coherent lidars in range-height indicator mode (in a vertical plane) to study vortices in the flow over mountainous terrain.

Recently, scanning lidars with a steerable scanner head have been developed that are able to point in any direction (Vasiljević et al., 2016). These lidars were used during the RUNE campaign, which was running during the winter of 2016 (Floors et al., 2016). This experiment took place in the west of Denmark and used four vertically profiling lidars on land, a lidar mounted on a floating buoy and three scanning lidars to map the flow in a transect across the coast.

In this study, our goal is to use the RUNE lidar measurements to document the performance of the WRF model in different setups. The model skill is evaluated by using vertical profiles, horizontal transects, Taylor diagrams, and velocity spectra. The vertical profile of wind speed is determined by the representation of turbulent mixing processes over surfaces with different roughness and stability conditions. The horizontal transects show the model's ability to capture changes in surface roughness resulting from the coastline. Taylor diagrams can identify which setup performs best. Finally, the impact of the model horizontal resolution is studied using modeled and observed velocity spectra. 

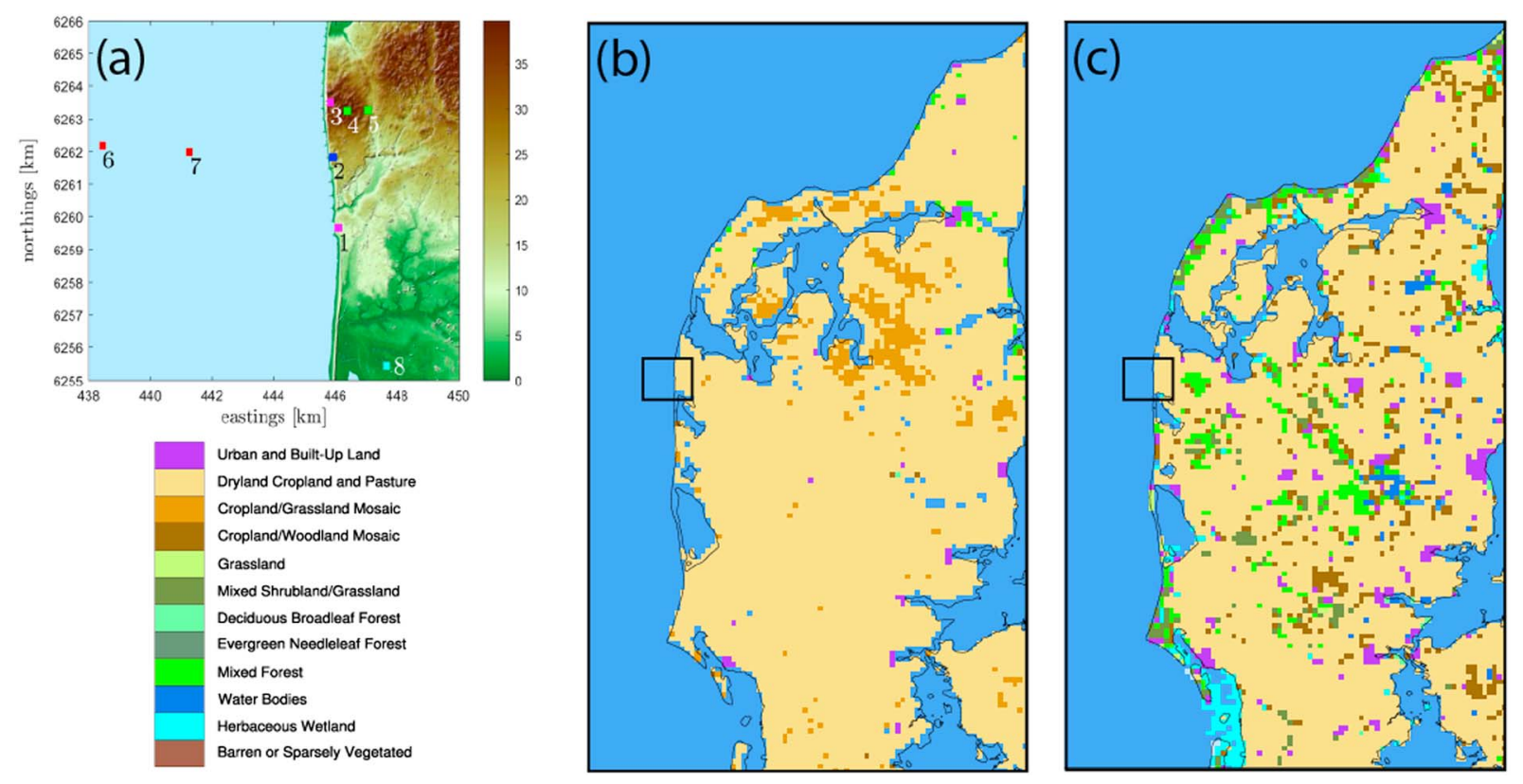

Figure 1. (a). Terrain height $(\mathrm{m})$ and the positions of the instruments denoted with numbered points (Table 1). The vertically profiling lidars WLS66 and Alizé are collocated with Vara in position 2. Land use description from the model simulations obtained from the (b) United States Geological Survey and (c) Coordination of Information on the Environment data set. The area of Figure 1a is denoted with a black rectangle.

In section 2 we describe the measurements and the experimental site. Details about the modeling setup and a description of the different sensitivity experiments are given in section 3 . In section 4.1, we evaluate the simulated vertical profile of mean wind speed at different locations and, in section 4.2, we compare the simulated mean horizontal wind speed gradient across the coast with the scanning lidar measurements. In section 4.3, Taylor diagrams are used to provide an overview of the performance of the different model setups. Finally, we study modeled and observed velocity spectra in section 4.4 .

\section{Measurements}

We use measurements from lidars and a mast obtained during the RUNE campaign, which started on 2 November 2015 and lasted until 1 March 2016 (Floors et al., 2016). It took place in the west of Denmark (see Figure 1), and the campaign was characterized by strong westerlies with several storms. There was a 2 week episode in January with easterly winds. The SST is higher than the advected air temperature over the North Sea during winter, so conditions were predominantly unstable. Over land conditions were mostly stable due to the negative radiation balance of the surface. The positions of all instruments are given in Figure 1a and Table 1. The instruments and measurements are described in detail in Floors et al. (2016). The data used in this paper are available for download (Floors et al., 2017).

The terrain of the experimental area is characterized by grass and crop fields with scattered houses and vegetation. The topography around the site is dominated by a steep cliff at the coast, whereas the terrain is undulating inland (see Figure 1a). To the north of the area, near position 3, the height of the cliff is $\approx 40 \mathrm{~m}$; near position 2 , the height of the cliff is $\approx 25 \mathrm{~m}$; and near position 1 , it becomes a dike of $\approx 15 \mathrm{~m}$.

\subsection{Vertical Profiling Lidars}

During the RUNE campaign, Leosphere pulsed Doppler lidars were used for vertical profiling (Table 1). To distinguish the lidars, we adopt the names that are given in Floors et al. (2016). Bura, 3E, WLS66, and the lidar buoy were all short-range lidars of the type WLS7, whereas Alizé is a long-range lidar of the type WLS70. The lidars WLS66 and Alizé were operating at position 2 . Bura and $3 E$ were installed $\approx 1 \mathrm{~km}$ and $400 \mathrm{~m}$ inland at positions 5 and 4, respectively. Another vertical profiling lidar was mounted on a buoy at position $6, \approx 8 \mathrm{~km}$ offshore. Due to high waves during a storm the power generator was damaged and therefore the lidar stopped working on 7 December. Due to bad weather and logistical issues, it was not possible to repair the power generator before 11 February. To avoid the influence of breaking waves, the buoy was moved to position 7. 
Table 1

Positions, Names, Types, Main Scanning Strategies (Usage) and Coordinates (UTM WGS84, Zone 32V) of the Lidars During the RUNE Campaign (See Details in the Text), Including the Information of the Høvsøre Meteorological Mast

\begin{tabular}{|c|c|c|c|c|c|c|c|c|c|c|}
\hline Position & Name & Type & Usage & Easting $(\mathrm{km})$ & Northing $(\mathrm{km})$ & Height amsl (m) & Start & End & $N$ & Recovery (\%) \\
\hline 1 & Koshava & WLS200S-007 & Dual setup & 446.1 & 6259.7 & 12.36 & $25 / 12$ & $17 / 02$ & 713 & 4.23 \\
\hline 2 & Vara & WLS200S-012 & Sector scan & 445.9 & 6261.8 & 26.38 & $26 / 11$ & $17 / 02$ & 713 & 4.23 \\
\hline 2 & Alizé & WLS70-001 & Vertical profile & 445.9 & 6261.8 & 26.38 & $09 / 11$ & $29 / 02$ & 9,866 & 57.09 \\
\hline 2 & WLS66 & WLS7-066 & Vertical profile & 445.9 & 6261.8 & 26.38 & $01 / 11$ & $29 / 02$ & 9,866 & 57.09 \\
\hline 3 & Sterenn & WLS200S-006 & Dual setup & 445.8 & 6263.5 & 42.97 & $26 / 11$ & $17 / 02$ & 713 & 4.23 \\
\hline 4 & $3 \mathrm{E}$ & WLS7-007 & Vertical profile & 446.4 & 6263.3 & 43.18 & $11 / 02$ & $01 / 03$ & 13,580 & 78.58 \\
\hline 5 & Bura & WLS7-002 & Vertical profile & 447.0 & 6263.3 & 24.93 & $12 / 11$ & $28 / 02$ & 10,910 & 63.13 \\
\hline 6 & Lidar Buoy Pos1 & WLS7-277 & Vertical profile & 438.4 & 6262.2 & 0.00 & $04 / 11$ & $07 / 12$ & 3,859 & 22.33 \\
\hline 7 & Lidar Buoy Pos2 & WLS7-277 & Vertical profile & 440.6 & 6262.1 & 0.00 & $11 / 02$ & $01 / 03$ & 1,375 & 7.96 \\
\hline 8 & Høvsøre mast & - & Mast & 447.6 & 6255.4 & 0.32 & $02 / 11$ & $01 / 03$ & 16,383 & 94.80 \\
\hline
\end{tabular}

Note. $N$ denotes the number of 10 min mean observations and the recovery percentage is given as a percentage of the total number of attainable 10-min intervals. The lidar buoy was used at two positions. The type is the commercial name given by the lidar manufacturer Leosphere.

The profiling lidars were configured to perform scans in a Velocity Azimuth Display mode, that is, the wind vector was reconstructed from the LOS velocities estimated at four azimuthal positions separated $90^{\circ}$ around the zenith. The sampling time for each azimuthal position was $\approx 3.5,1,1,5$, and $1 \mathrm{~s}$ for Bura, 3E, WLS66, Alizé, and the lidar buoy, respectively. The height up to which lidars can measure depends on the average aerosol load and the power of the laser. To assure good quality data, measurements with a carrier-to-noise ratio (CNR) lower than $-22 \mathrm{~dB}$ are filtered out for all lidars; a limit of $-32 \mathrm{~dB}$ is used for Alizé, and this lidar can measure up to 2,000 m height (Gryning et al., 2016). These limits were chosen to increase the correlation between the wind speeds obtained from the lidars with those observed at the meteorological mast and to still have enough samples left for the evaluation. Wind speed and wind direction measurements up to 500, 250, and $130 \mathrm{~m}$ above the surface were used from Alizé, the lidar buoys, and the other lidars, respectively. The lowest height at which the lidars were measuring was $30 \mathrm{~m}$, and all measurement heights are given in Table 3 in Floors et al. (2016).

For each of the lidars, the recovery rate is shown in Table 1, which is defined as the percentage of data that fulfilled the filtering criteria divided by the 17,281 ten-minute periods covering the whole campaign. Note that Alizé and Bura did not start measuring before 9 and 12 November, respectively, which partially explains the lower recovery percentage compared to the mast (position 8 in Figure 1). The lidar buoy recovery rate is much lower than that of the other lidars due to the technical problems, and its measurements are split over the two locations (see Table 1).

In homogeneous conditions, the uncertainty on the wind speeds obtained from vertically profiling lidars is as low as those from cup anemometers (Gottschall \& Courtney, 2010). It was shown in Floors et al. (2016) that Alizé had a positive $3 \%$ bias compared to WLS66. This was attributed to the differences in their measuring volume and the inhomogeneous flow near the cliff; Bingö et al. (2009) showed that horizontal wind speeds obtained from a conically scanning lidar were up to $10 \%$ different from those from a cup anemometer in terrain where the streamlines were not horizontal. The lidar $3 \mathrm{E}$ measured a mean wind speed that was $\approx 1 \%$ higher than that from Bura, because they are nearly a kilometer apart.

\subsection{Scanning Lidars}

The scanning lidars used in the current study are modified versions of the WindCube 200S from the company Leosphere and have been successfully used in several field campaigns (Vasiljević et al., 2016). During the RUNE experiment, the scanning lidars were placed on top of the cliff to have an unobstructed LOS. Different scanning patterns were configured, but in this study we only use the measurements obtained between 26 November and 17 February. The lidars Koshava and Sterenn used a "dual setup" to scan three virtual horizontal lines at 50,100 , and $150 \mathrm{~m}$ above mean sea level (amsl) from $\approx 5 \mathrm{~km}$ offshore up to $\approx 4 \mathrm{~km}$ inland (Figure 2) by moving the scanner heads to the same points.

The lidar Vara performed a plan position indicator scan or sector-scan setup (Figure 2); it scanned $60^{\circ}$ of an azimuthal plane up to $\approx 8 \mathrm{~km}$ distance. This plane was sampled at three different elevation angles, such that 


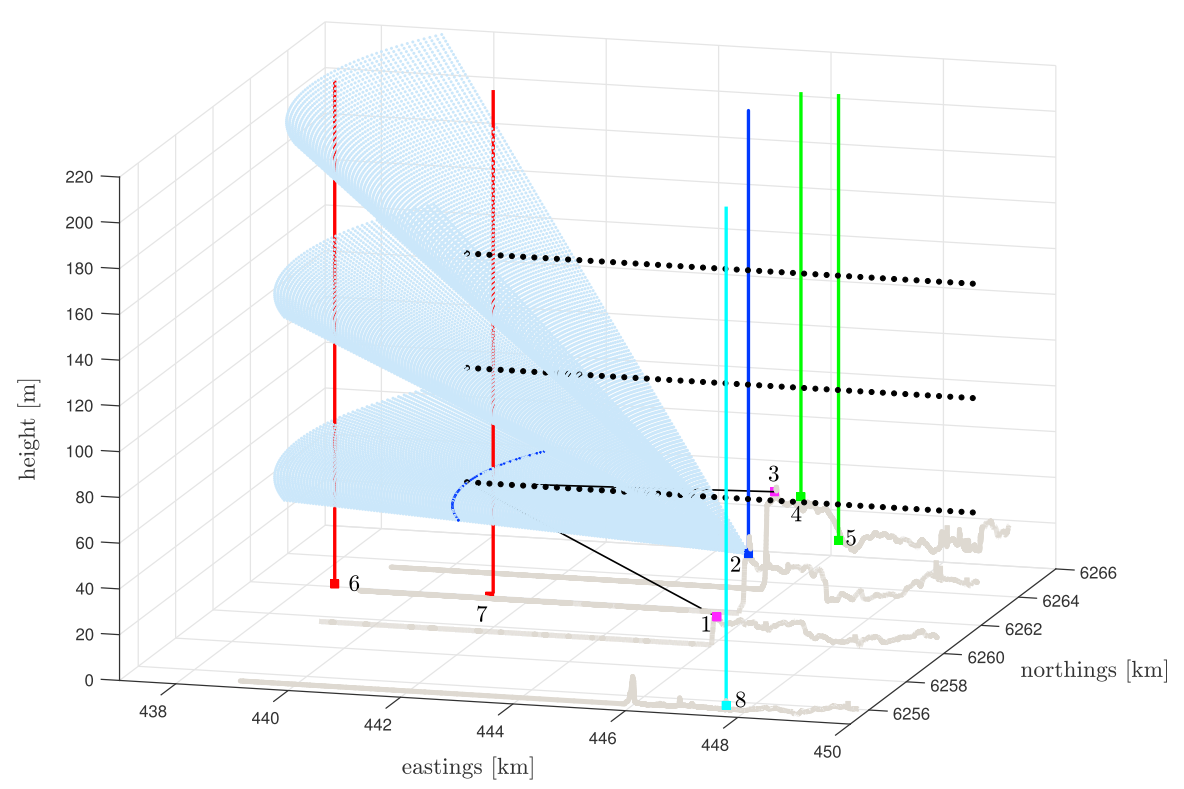

Figure 2. Overview of the main scanning patterns during the measurement campaign. The light blue points denote the sector scan from Vara, the black dots the collocated range gates from Sterenn and Koshava, the green lines the lidars $3 \mathrm{E}$ and Bura, the dark blue lines the lidars WLS66 and Alizé, the light blue line the Høvsøre meteorological mast, and the red lines the lidar buoy. The dark blue points from the sector scan denote an arch from which the wind vector can be reconstructed.

these planes approximately intersected with the height of the three dual setup sampling points $\approx 5 \mathrm{~km}$ offshore at 50,100 , and $150 \mathrm{~m}$ amsl. Both the dual and sector-scan setups performed a full scan in $\approx 145 \mathrm{~s}$, which consisted of three $45 \mathrm{~s}$ scans at each elevation and $10 \mathrm{~s}$ to move the scanner heads back to the starting positions. The four available $1 \mathrm{~s}$ samples of the LOS wind speed in each point were used to reconstruct the wind speed components as described in Appendix A and averaged in 10 min means. The 10 min period is chosen because most of the other measurements averaged within this interval.

The availability of the scanning lidars is lower than that of the lidars in Velocity Azimuth Display mode because of the long distance to the sampling point. Similar to the profiling lidars, we require measurements in all range gates to fulfill a CNR threshold. For the dual setup, the CNR limit was $-26.5 \mathrm{~dB}$, whereas for the lidar in sector-scan mode it was $-27 \mathrm{~dB}$, due to small differences between the power of the lasers in each device. The lidar beam hits objects in the eastward direction after $\approx 2 \mathrm{~km}$, and therefore, transects in the range from $5,000 \mathrm{~m}$ west to 2,000 $\mathrm{m}$ east of Vara were used. Sampling points from the dual setup between $x=445,615$ and 446,215 m (UTM WGS84, zone 32V) were removed because the uncertainty in reconstruction of the wind speed is too large when the angle between the LOS is more than $\approx 150^{\circ}$; Vasiljević and Courtney (2017) estimated the uncertainty in each point of the dual setup and found that $<500 \mathrm{~m}$ near the coast the uncertainty is $>0.5 \mathrm{~m} \mathrm{~s}^{-1}$, whereas at a distance $>1 \mathrm{~km}$ the uncertainty was $<0.2 \mathrm{~m} \mathrm{~s}^{-1}$.

To study the horizontal transects, 10 min measurements that simultaneously satisfied the quality control requirements were selected from the sector scan, the dual setup, and the vertical profiling lidars. After filtering, 731 ten-minute transects remained, that is, a recovery rate of $4.23 \%$. Because during the episode with easterly winds the air contained very little aerosols, the number of $10 \mathrm{~min}$ transects with winds from an easterly direction is only 32 .

Although the uncertainty on the retrieval of the LOS velocity at a known location is low, there are additional uncertainties related to the LOS position, that is, errors in the elevation angle, in the azimuth angle, and in the detected range. A detailed account of each term is given in Vasiljević et al. (2016).

\subsection{Meteorological Mast}

The Høvsøre meteorological mast is located $\approx 6 \mathrm{~km}$ south and $\approx 2 \mathrm{~km}$ inland of Vara (position 8 in Figure 1 a). The measurements performed at this mast are thoroughly quality controlled (Peña et al., 2016). We use the $10 \mathrm{~min}$ mean wind speeds obtained with Ris $\varnothing$ cup anemometers at the southern side of the mast at 10,40,60,80, 100, 


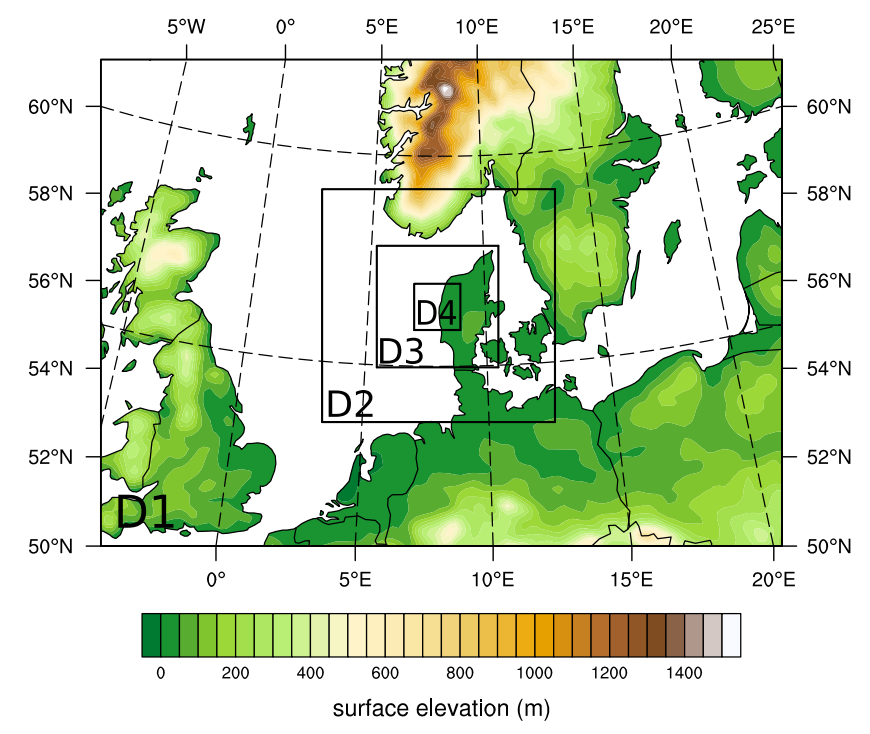

Figure 3. Surface elevation $(m)$ of the outer model domain with the location of nested model domains indicated. The horizontal grid spacing for domain D1 was 18,12 , and $13.5 \mathrm{~km}$ (see Table 2), and the grid spacing decreased with a factor of 3 in each nested domain. D4 was only used for the runs with $13.5 \mathrm{~km}$ grid spacing in D1. and $160 \mathrm{~m}$. The wind direction is measured at 10,60 , and $100 \mathrm{~m}$. Horizontal velocity spectra are computed from the cup anemometer at $100 \mathrm{~m}$ height. The measuring frequency of the cup anemometer is $10 \mathrm{~Hz}$, but here we are only interested in mesoscale fluctuations, and therefore, the measurements were down-sampled to $0.1 \mathrm{~Hz}$. The measurements were linearly interpolated to fill missing data in the $0.1 \mathrm{~Hz}$ time series. A fast-Fourier transform was performed on linearly detrended $\approx 14$ day periods ( $2^{11}$ ten-minute periods).

\section{Mesoscale Modeling}

\subsection{Basic Setup}

We use the WRF model to perform simulations during the measurement period (Skamarock et al., 2008). We used version 3.6, to which patches and bug fixes were applied that are described at http://www2.mmm.ucar.edu/wrf/users/wrfv3.6/known-prob-3.6.html There were 70 vertical model levels, with its highest density near the surface (every $\approx 10 \mathrm{~m}$ in the first $100 \mathrm{~m}$ ). The WRF model top was set at $50 \mathrm{hPa}$. The first model level was at $11 \mathrm{~m}$ above the surface, and there were eight model levels within the first $100 \mathrm{~m}$. The model domains are shown in Figure 3 and cover a large part of northwestern Europe. One-way nested domains with a grid spacing ratio of 3 between the parent and child nests were used. The grid spacings of the different setups are presented in section 3.2.2. The domain boundaries were chosen such that they were at approximately the same geographical location for all setups with different horizontal grid spacings.

The simulations were initialized everyday at 0000 UTC and were integrated for $36 \mathrm{~h}$. The first $12 \mathrm{~h}$ were disregarded as model spin-up period. The instantaneous output of the model was saved every $10 \mathrm{~min}$ for the third and fourth nested domains and hourly for the other domains. The model time step was $65.45 \mathrm{~s}$ in the outermost domain and decreased with the same factor as the model grid spacing for the nested domains. This time step was chosen to ensure that the model time step and output interval were collocated in all nested domains (Skamarock et al., 2008).

Spectral nudging was used above the 25 th model level (roughly equal to the mean PBL height at $\approx 600 \mathrm{~m}$ ), and it was always set to zero at model levels lower than the PBL height, to avoid that the model drifts too much from the large-scale synoptic conditions (Radu et al., 2008). The nudging coefficient was set to $0.0003 \mathrm{~s}^{-1}$ for wind, temperature, and specific humidity. This is done to avoid nudging to local effects present in the atmospheric (re)analysis data (e.g., Radu et al., 2008). Vincent and Hahmann (2015) showed that WRF simulations of $36 \mathrm{~h}$ length had a more realistic representation of the mesoscale variance compared to 11 day simulations. Furthermore, using spectral nudging resulted in a slightly more realistic representation of the mesoscale variance than using grid nudging. Before the simulations that are presented in this study were started, we performed another sensitivity study with simulations with a length of 2 to 10 days: all simulations that were spectrally nudged had a higher Pearson correlation coefficient between modeled and observed wind speeds at all heights at two high masts in Denmark than those that were not nudged, even for a simulation length of 2 days. Therefore, the setup described here was found adequate to capture the flow characteristics.

The physical parametrizations options included the WRF single-moment 5-class microphysics scheme, the Kain-Fritsch cumulus parameterization (turned off in domains 3 and 4), the Rapid Radiative Transfer Model for Global Circulation Models scheme for short- and long-wave radiation, and the Noah land surface model.

The wind speeds were obtained from the lowest 34 model levels and vertically logarithmically interpolated to the heights of the observations. Horizontally, the grid points closest to the positions where observations were available were extracted.

\subsection{Sensitivity Studies}

The following model sensitivity studies were performed to investigate the impact on the model performance in the experimental area. All simulations were performed on Technical University of Denmark's (DTU) 
Table 2

Abbreviated Name, the Atmospheric Boundary Conditions, PBL Scheme, SST Source, Land Cover Source, and the Horizontal Resolution of the Innermost Domain of the Modeling Setups Used During the RUNE Campaign

\begin{tabular}{|c|c|c|c|c|c|}
\hline $\begin{array}{l}\text { Model } \\
\text { simulation }\end{array}$ & $\begin{array}{c}\text { Atmospheric } \\
\text { boundary conditions }\end{array}$ & $\begin{array}{c}\text { PBL } \\
\text { scheme }\end{array}$ & $\begin{array}{c}\text { SST } \\
\text { source }\end{array}$ & $\begin{array}{l}\text { Land cover } \\
\text { source }\end{array}$ & $\begin{array}{l}\text { Horizontal } \\
\text { grid spacing }(\mathrm{km})\end{array}$ \\
\hline $\mathrm{YSU}_{2}$ & FNL & YSU & DMI & CORINE & 2 \\
\hline $\mathrm{YSU}_{1}$ & FNL & YSU & DMI & CORINE & 1 \\
\hline $\mathrm{YSU}_{0.5}$ & FNL & YSU & DMI & CORINE & 0.5 \\
\hline $\mathrm{MYJ}_{2}$ & FNL & MYJ & DMI & CORINE & 2 \\
\hline $\mathrm{MYJ}_{1}$ & FNL & MYJ & DMI & CORINE & 1 \\
\hline $\mathrm{MYJ}_{0.5}$ & FNL & MYJ & DMI & CORINE & 0.5 \\
\hline YSU $_{\text {HRSST }}$ & FNL & YSU & $\mathrm{HR}$ & CORINE & 2 \\
\hline MYJ $_{\text {HRSST }}$ & FNL & MYJ & $\mathrm{HR}$ & CORINE & 2 \\
\hline YSU USGS $_{\text {US }}$ & FNL & YSU & DMI & USGS & 2 \\
\hline MYJ USGS $_{\text {US }}$ & FNL & MYJ & DMI & USGS & 2 \\
\hline $\mathrm{YSU}_{\text {ERA }}$ & ERA & YSU & DMI & CORINE & 2 \\
\hline$M \mathrm{~J}_{\text {ERA }}$ & ERA & MYJ & DMI & CORINE & 2 \\
\hline
\end{tabular}

Note. USGS = United States Geological Survey; CORINE = Coordination of Information on the Environment; YSU = Yonsei University; MYJ = Mellor-Yamada Janjic; DMI = Danish Meteorological Institute; FNL = Final Analysis; HR = high resolution; HRSST $=$ High-Resolution Sea Surface Temperature.

high-performance cluster "Jess," which has 320 nodes with 20 CPUs each. A 36 h simulation with 0.5, 1, and $2 \mathrm{~km}$ grid spacing in the innermost domain required $\approx 125,65$, and 22 CPU hours to complete, respectively.

\subsubsection{PBL Scheme}

The first-order Yonsei University (YSU) and the 1.5-order Mellor-Yamada Janjic (MYJ) closure schemes were used to represent the PBL (Janjić, 1990; Noh et al., 2003) (see Table 2). First-order schemes express the eddy diffusivity directly (Troen \& Mahrt, 1986), whereas 1.5-order schemes use a prognostic turbulence kinetic energy equation (Mellor et al., 1982). Svensson and Holtslag (2009) showed that operational first-order PBL schemes had a too low cross-isobaric wind component and surface stress in the stable boundary layer compared to higher-order schemes.

The YSU scheme includes a term to model the effect of nonlocal mixing, whereas the MYJ scheme does not (Xie et al., 2012). Local turbulent closures cannot realistically model a convective boundary layer with near-zero gradients in wind speed or temperature (Shin \& Dudhia, 2016). An overview of differences between PBL schemes that are implemented in the WRF model is given in Cohen et al. (2015). All sensitivity setups introduced later were performed with both PBL schemes.

\subsubsection{Horizontal Grid Spacing}

Three different horizontal grid spacings were used. The first setup has a spacing of 18,6 , and $2 \mathrm{~km}$ for the outermost, middle, and innermost domain, respectively. The second setup uses 9,3 , and $1 \mathrm{~km}$ in those domains, and the finest spacing used four nested domains with a spacing of $13.5,4.5,1.5$, and $0.5 \mathrm{~km}$. The resolution of the innermost domain is used as a subscript in Table 2. Despite the relatively high resolution, there is still a difference of $\approx 20 \mathrm{~m}$ between the observed terrain elevation and that used as input for the simulations with the finest horizontal grid spacing at the position of the cliff. That is partly because the resolution is insufficient in the elevation data itself (see section 3.2.3), but mostly because the WRF model needs input data that are interpolated to a coarser model grid.

Wyngaard (2004) introduced the concept of modeling in the "terra incognita," that is, when the scale of the spatial filter of a mesoscale model is similar to the dominant length scale of the flow. For a convective boundary layer, this characteristic scale is about $1 \mathrm{~km}$, and therefore, some of our simulations can partially resolve turbulence. However, the PBL schemes in a mesoscale model are developed under the assumption that all turbulent motions are in the subgrid scale. Because the RUNE experiment took place during winter, stable and neutral conditions prevail over land and the turbulent eddies are expected to be smaller than in unstable 

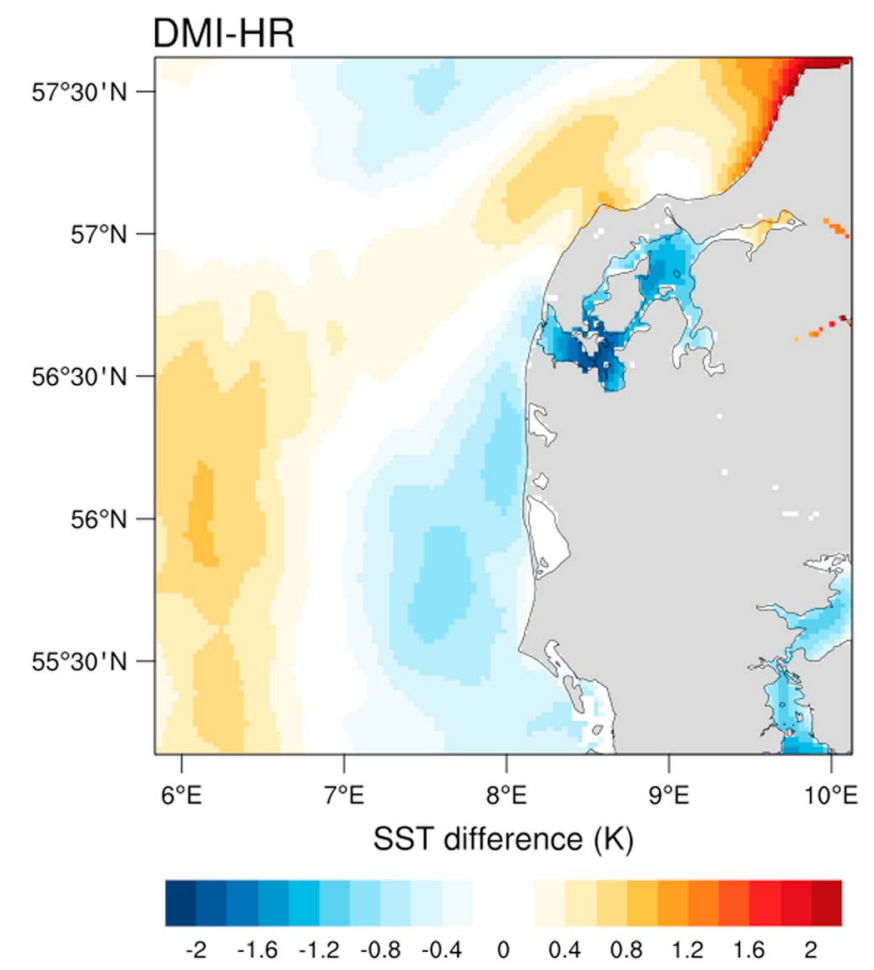

Figure 4. The mean SST difference between the DMI and HR data on the $2 \mathrm{~km}$ WRF grid between 2 November 2015 and 1 March 2016. conditions. On the other hand, cold-air advection over a warm North Sea can still result in unstable boundary layers; during $15 \%$ of the time of the campaign the modeled PBL height at position 7 was more than 1,000 $\mathrm{m}$.

\subsubsection{Terrain Elevation and Land Use}

The description of the land cover is important to correctly assign the surface albedo, the emissivity, and the roughness length to the land around the experimental area. In this study, the land use is also vital for correctly positioning the coastline. The standard land use description that is often used with the WRF model is based on the 24-category United States Geological Survey (USGS) data (Anderson et al., 1976). However, it is a rather outdated data set that represents the land use conditions in 1992 (Nielsen, 2013). In the USGS data set the main land use in Denmark is cropland, with very few forests and built-up areas (Figure 1b).

A more recent attempt to describe the land use in Europe was made as part of the CORINE project. The resulting data set is freely available online (https://www.eea.europa.eu/data-and-maps/data/clc-2006-raster-3). The version used here reflects the land use situation in 2006 and has a grid spacing of $250 \mathrm{~m}$. The CORINE data are divided in 44 categories, but these were reassigned to the same 24 categories as the USGS data (Pindea et al., 2002). In the CORINE data set, Denmark has many scattered villages and forests, which is more realistic than the rather homogeneous landscape in the USGS data (see Figures $1 \mathrm{~b}$ and $1 \mathrm{c}$ ).

The 25th land use category is reserved for describing lakes. This can be important in Denmark, because inland water bodies can freeze during winter and can therefore have a water temperature that is very different from that of the North Sea. The water temperature from a lake in WRF is estimated from the averaged soil temperature in the driving (re)analysis, whereas the SST is determined from a different external data source. Around the experimental site there are several lakes and fjords.

Modified Shuttle Radar Topography Mission data with a horizontal grid spacing of $90 \mathrm{~m}$ was used for describing the terrain elevation in the WRF model. In these data, several known artifacts in the Shuttle Radar Topography Mission data have been corrected (see http://www.viewfinderpanoramas.org/dem3.html). The files were converted to binary tiles that can be read by the "geogrid" utility that interpolates data to the grid needed by the WRF model.

\subsubsection{Sea Surface Temperature}

To investigate the impact of the SST on the simulations, we used two different data sources. The first product is a real-time global daily high-resolution (HR) SST analysis from the National Centers of Environmental Prediction. The resolution of this product is $1 / 12^{\circ}$ (Gemmill et al., 2007). In Table 2, this SST product is abbreviated as HR.

In winter, there can be significant gradients in SST near the coast in Denmark. A product that resolves well these strong SST gradients near the coast is the new high-resolution SST data set developed by the Danish Meteorological Institute (DMI). The Level 4 DMI North Sea-Baltic Sea daily analysis has a resolution of $0.02^{\circ}$ (Høyer \& Karagali, 2016). It was specifically developed taking into consideration the conditions occurring in the Scandinavian region. These data were provided by the Group for High Resolution Sea Surface Temperature, $\mathrm{DMI}$, and the MyOcean regional data assembly center.

The mean SST difference between the DMI and HR data on the $2 \mathrm{~km}$ WRF grid is shown in Figure 4. The difference between the two data sources during the RUNE experimental period at positions 6 and 7 is $\approx 0.6^{\circ} \mathrm{C}$, but in other places it is higher; at the northern tip of Jutland, the DMI data set has a mean SST that is $\approx 2^{\circ} \mathrm{C}$ warmer than the HR data set. Near the south coast of Denmark, there are areas where the DMI data set has a SST that is $\approx 1^{\circ} \mathrm{C}$ colder than those from the HR data set.

\subsubsection{Atmospheric Boundary Conditions}

The atmospheric initial and boundary conditions that drive the mesoscale model can greatly influence the mean wind speed and model skill (Floors et al., 2013). Therefore, data from the Final Analysis (FNL) from 
the National Centers of Environmental Prediction (National Centers for Environmental Prediction/National Weather Service/NOAA/U.S. Department of Commerce, 2015) and the ERA-Interim Reanalysis from the European Centre for Medium-Range Weather Forecasts (Dee et al., 2011) were used here.

Initially, all simulations were performed with the FNL data, because these were available near real time. All simulations were performed with a delay of $\approx 2$ days. The ERA-Interim data are available with a delay of $\approx 2$ months. Because more observations have been assimilated in this data set compared to FNL, it is more likely that the simulations will represent most closely the atmospheric conditions during the campaign. Furthermore, it uses a four-dimensional variational data assimilation system, whereas the FNL data are based on a three-dimensional system (Dee et al., 2011). The horizontal grid spacing of the FNL data is $0.25^{\circ}$, whereas it is $0.75^{\circ}$ for the ERA-Interim data. Carvalho et al. (2014) compared WRF simulations driven by different atmospheric boundary conditions and found that simulations using ERA-Interim data had the best agreement compared to observations from thirteen $60 \mathrm{~m}$ masts.

\subsection{Taylor Diagrams}

In addition to mean profiles of wind speed, we use Taylor diagrams to compare the model performance with the measurements in more detail (Taylor, 2001). These diagrams combine the correlation coefficient $(R)$, centered root-mean-square error (RMSE), and standard deviation $(\sigma)$ of observed and modeled variables. The correlation coefficient, $R$, is defined as

$$
R=\frac{1}{\sigma_{x} \sigma_{y}} \frac{1}{N} \sum_{i=1}^{N}\left(x_{i}-\bar{x}\right)\left(y_{i}-\bar{y}\right),
$$

where $N$ is the number of samples, $x_{i}$ is the observed variable, $y_{i}$ is the modeled variable, and the overbar and $\sigma$ denote their mean and standard deviation, respectively. The centered RMSE is defined as

$$
\operatorname{RMSE}=\sqrt{\frac{1}{N} \sum_{i=1}^{N}\left[\left(x_{i}-\bar{x}\right)-\left(y_{i}-\bar{y}\right)\right]^{2}}
$$

\section{Results}

\subsection{Vertical Profiles}

The mean wind speed from the vertically profiling lidars and the mast and those simulated by WRF using the MYJ scheme are shown in Figure 5. For each panel the observations and the model results were merged for each available time stamp, so that they are concurrent. The panels are ordered by increasing longitudinal position, that is, moving eastward.

Offshore, at locations 6 and 7, the mean wind speed at the lowest observed level is much higher than over land. Note that these locations have a shorter observation period and consequently a higher standard error of the mean, $s_{e}=\sigma / \sqrt{N}$, than the inland locations (see error bars in Figure 5). At all heights, the simulated mean wind speed is lower than that observed. The $\mathrm{MYJ}_{0.5}$ simulation has the highest mean wind speed at $500 \mathrm{~m}$, whereas the MYJ $\mathrm{HRSST}_{\mathrm{T}}$ simulation shows the highest mean wind speed near the surface.

At location 2 (at the coast), there are available measurements from both short- and long-range lidars. It can be seen that all model simulations underestimate the mean wind speed at all heights. At $40 \mathrm{~m}$ above the surface, the bias is largest and $\approx-0.7 \mathrm{~m} \mathrm{~s}^{-1}$ using the $\mathrm{MYJ}_{0.5}$ simulation. The mean wind speed near the ground is high due to the lidar position close to sea, where the wind speed is likely influenced by an orographic speedup resulting from the cliff.

At location 4, that is, $\approx 1 \mathrm{~km}$ inland, the mean wind speed near the ground has decreased due to the effect of local topography. All model simulations represent the mean wind speed at this location quite well, despite an underestimation of $\approx 0.3 \mathrm{~m} \mathrm{~s}^{-1}$ at $125 \mathrm{~m}$. At location 5 , that is, $\approx 1.5 \mathrm{~km}$ inland, all model simulations overestimate the mean wind speed with $\approx 0.3 \mathrm{~m} \mathrm{~s}^{-1}$.

Location 8 (meteorological mast) is the most inland location and identified from the observed low mean wind speeds at $10 \mathrm{~m}$. Here the MYJ USGS simulation has a much higher wind speed near the surface than the other simulations, which is a consequence of the reduced surface roughness in the simulation using the USGS land use (see Figure 1b). At $500 \mathrm{~m}$ above the surface, the differences in mean wind speed between the different simulations are negligible. 
a) Lidar buoy (Loc. 6)

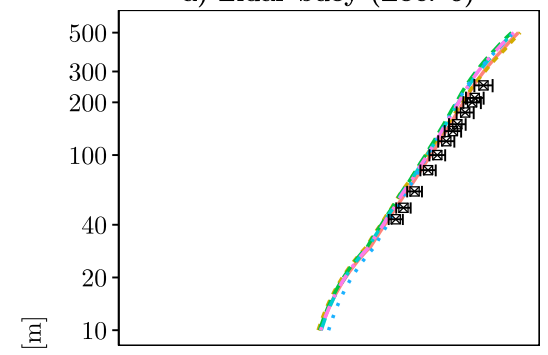

d) $3 \mathrm{E}$ (Loc. 4)

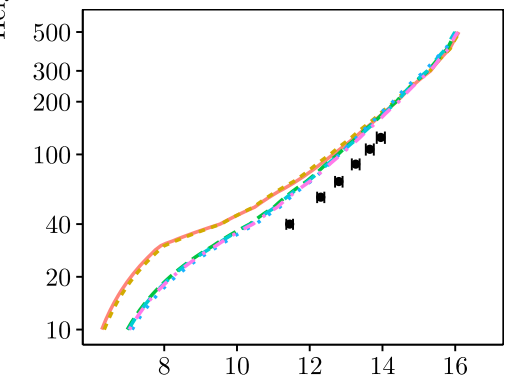

b) Lidar buoy (Loc. 7)

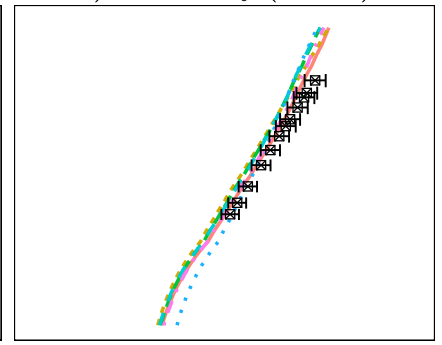

e) Bura (Loc. 5)

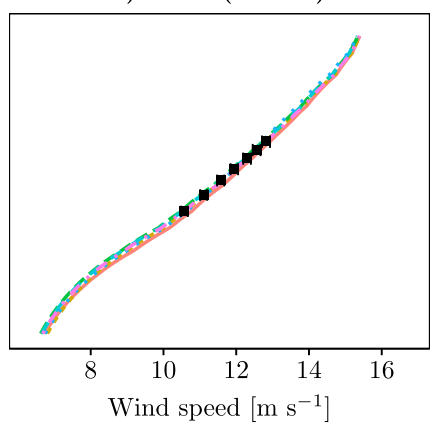

c) WLS66 (Loc. 2)

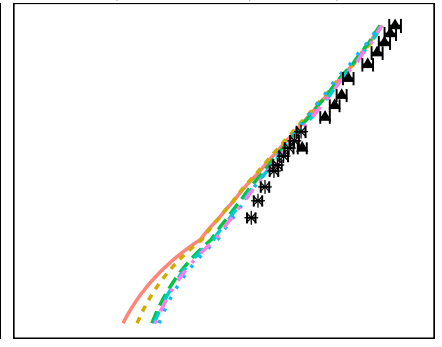

f) Høvsøre Mast (Loc. 8)

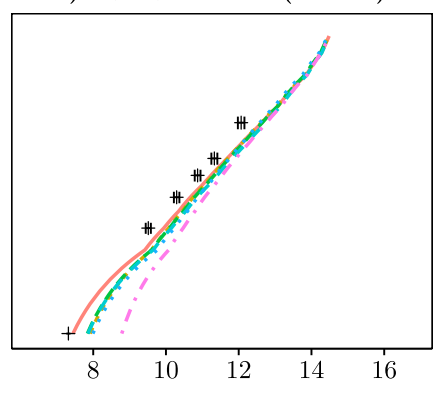

- $\quad 3 \mathrm{E}$

- Alizé

- Bura

$+\quad H \varnothing v s \varnothing r e ~ M a s t$

$\bowtie \quad$ Lidar buoy

* WLS66

Figure 5. The mean simulated and observed wind speed $\left(\mathrm{m} \mathrm{s}^{-1}\right)$ as a function of height $(10-500 \mathrm{~m})$ during the RUNE campaign using the simulations with the Mellor-Yamada Janjic (MYJ) Planetary Boundary Layer scheme (Table 2) at different locations moving from west to east (Table 1). The errors bars denote the standard error of the mean, $s_{e}=\sigma / \sqrt{N}$. The number of available 10 min intervals for each panel is shown in Table 1. HRSST = High-Resolution Sea Surface Temperature; USGS = United States Geological Survey.

All the simulations that used the YSU PBL scheme are shown in Figure 6. Generally, the results are very similar to those using the MYJ scheme (Figure 6), except at the two offshore locations 6 and 7. Here all simulations with the YSU scheme have a smaller bias than those using the MYJ scheme. The difference in mean wind speed between the model simulations and the observations is very small $\left(\lesssim 0.1 \mathrm{~m} \mathrm{~s}^{-1}\right)$ at location 6 .

\subsection{Cross Sections}

In this section, we evaluate the mean wind speed across the experimental site from $5 \mathrm{~km}$ offshore up to 2 $\mathrm{km}$ inland. We required that all sampling points fulfilled the quality criteria that are discussed in section 2.2. Furthermore, we require availability of the vertically profiling lidars during the same period, to be able to compare the two data sources. Finally, we can compare the sector scan that has some sampling points at the same locations as the dual setup. An all-sector mean wind speeds at all the dual-setup locations using the 731 ten-minute periods at 50, 100, and $150 \mathrm{~m}$ amsl that remained after filtering are shown in Figure 7. The error bars denote the standard error of the mean, although there is additional measurement uncertainty related to the positional accuracy of the measurement volume and the reconstruction of the wind vector (see section 2.2). The model output from all simulations was extracted during the same 10 min intervals.

At $50 \mathrm{~m}$ amsl and at $5 \mathrm{~km}$ offshore, the mean simulated wind speed is slightly higher than that observed with the dual setup. The sector scan shows a mean wind speed that is $\approx 0.3 \mathrm{~m} \mathrm{~s}^{-1}$ higher than that of the dual-Doppler lidar retrievals mainly due to the problems of accurately reconstructing a wind speed when the wind is perpendicular to the LOS (Floors et al., 2016). Near the coast, this problem is less pronounced due to the shorter arc-length and the mean wind speed from the dual and sector-scan setups agrees well.

East of the coastline, the observed mean wind speed from the dual-Doppler lidar retrievals at $50 \mathrm{~m}$ amsl is significantly lower than that simulated. This is likely because the flow in the mesoscale model needs a few grid points to adjust to the new logarithmic wind profile that results from the higher surface roughness. Furthermore, the real terrain height is higher than that in the simulations, which causes the wind speeds obtained from the dual-Doppler lidar retrievals to be closer to the surface. This is because the measurements 
a) Lidar buoy (Loc. 6)

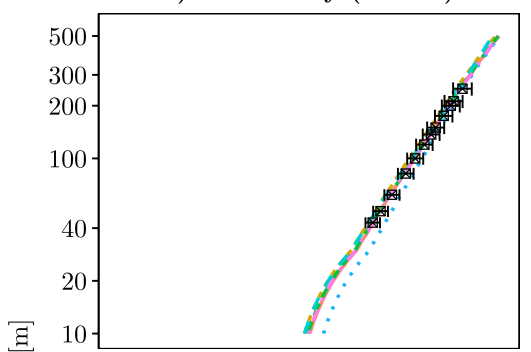

d) $3 \mathrm{E}$ (Loc. 4)

莺

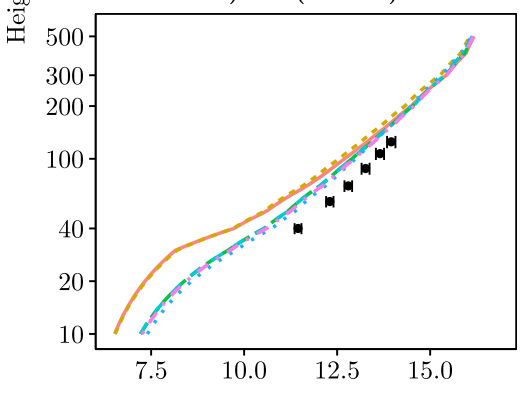

b) Lidar buoy (Loc. 7)

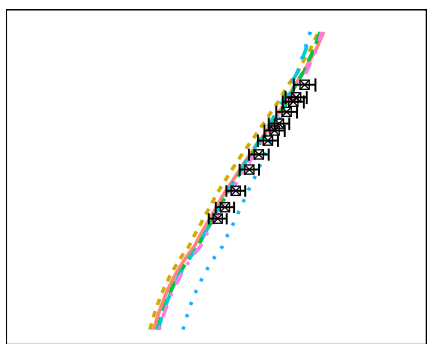

e) Bura (Loc. 5)

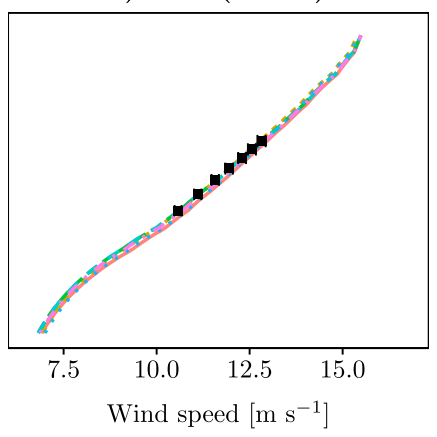

c) WLS66 (Loc. 2)

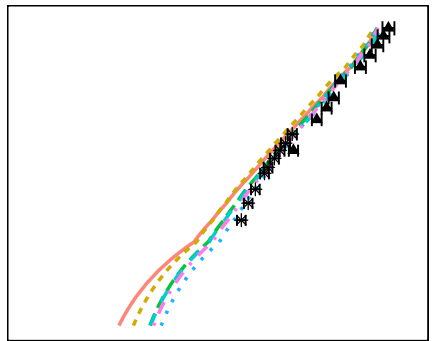

f) Høvsøre Mast (Loc. 8)

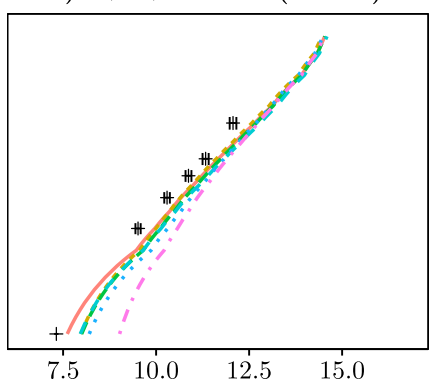

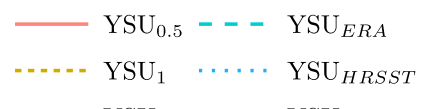

- $3 \mathrm{E}$

- Alizé

- Bura

$+\quad$ Høvsøre Mast

\ Lidar buoy

$---=\mathrm{YSU}_{2},-\cdots \mathrm{YSU}_{U S G S}$

Figure 6. As in Figure 5 but with the Yonsei University (YSU) Planetary Boundary Layer scheme. HRSST = High-Resolution Sea Surface Temperature; USGS = United States Geological Survey.

and simulations could only be compared at a height relative to sea level and not to the surface (see section 2.2). The effect of horizontal resolution is visible by the strong decrease in wind speed near the coastline of the simulations with highest horizontal resolution, $\mathrm{YSU}_{0.5}$ and $\mathrm{MYJ}_{0.5}$, that can better resolve the fast deceleration of the flow. Moving toward the land from an offshore position closer to the coastline, the mean wind speed from the dual-Doppler lidar retrievals decreases more than that from the model simulations. This is probably due to flow blocking effect of the cliff, which is not represented in the WRF model simulations.

At the farthest offshore position reached by the dual-Doppler lidar retrievals at $50 \mathrm{~m}$ amsl, the YSU HRSST $_{\text {, }}$

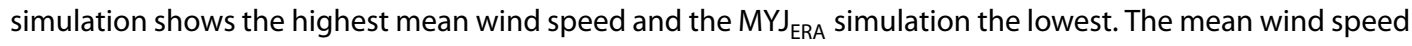
from all the simulations differs by less than $0.5 \mathrm{~m} \mathrm{~s}^{-1}$, so the sensitivity of the mean wind speed gradient to the different model setups is quite low. However, most YSU simulations show a stronger decrease of the mean wind speed eastward of the coastline and higher offshore mean wind speeds compared to the MYJ simulations. A more detailed description of model performance is given in section 4.3.

At $100 \mathrm{~m}$ amsl, all simulations overpredict the mean wind speed both offshore and onshore. The $\mathrm{YSU}_{0.5}$ simulation shows the highest mean wind speed. Although the vertically profiling lidars do not measure the wind in the same exact position as the dual setup, the mean wind speed from the vertically profiling lidars also decreases moving from the coastline inland. The mean wind speed from $3 E$ and Bura is lower than that from the dual-Doppler lidar retrievals, mainly due to the terrain height at those positions; Bura and 3E measured closer to the ground than WLS66.

At $150 \mathrm{~m}$ amsl the east-west gradient in mean wind speed is less pronounced than at 50 and $100 \mathrm{~m}$ amsl. This is due to the smaller influence of the land at these heights. Still, all model simulations overpredict (by $0.5-0.8 \mathrm{~m} \mathrm{~s}^{-1}$ ) the mean wind speed compared to the dual-Doppler lidar retrievals.

One could argue that the strict filtering can cause the cross sections to not be representative of the mean wind conditions of the 4 month period. Thus, we also studied the mean wind speed for a shorter scanning distance offshore, such that more transects were available. Including transects that extend to no more than $2 \mathrm{~km}$ away 
a) $50 \mathrm{~m}$ asl

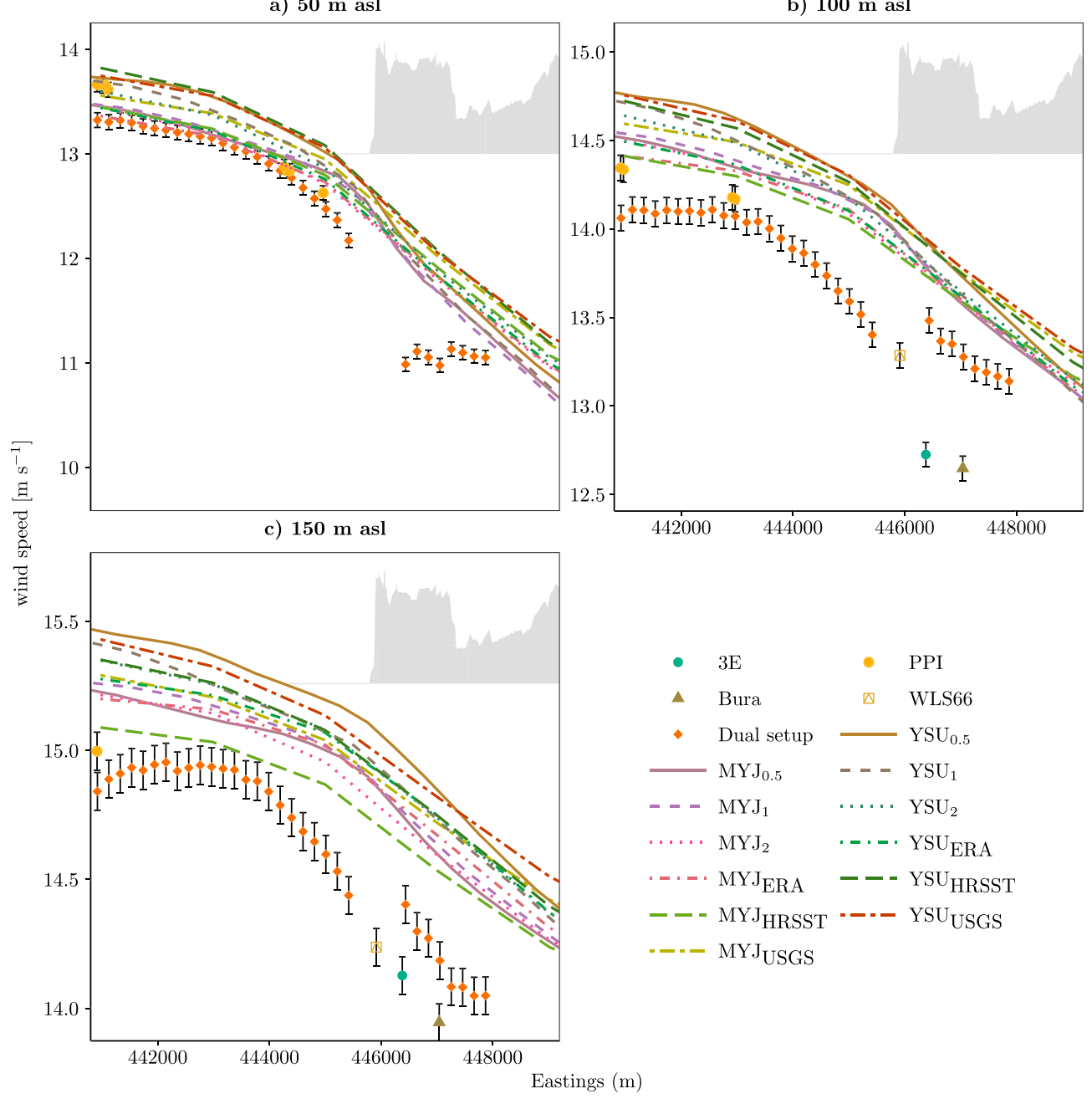

Figure 7. The reconstructed mean wind speed obtained from the sector-scan and dual setups and the vertical profiling lidars between 5,000 $\mathrm{m}$ offshore and 2,000 m inland (points) and the simulations (lines, Table 2) at three heights amsl: $50 \mathrm{~m}(\mathrm{a}), 100 \mathrm{~m}$ (b), and $150 \mathrm{~m}$ (c). The error bars denote the standard error of the mean. The gray pattern on the upper right denotes the terrain height (not to scale of $y$ axis). USGS = United States Geological Survey; YSU = Yonsei University; MYJ = Mellor-Yamada Janjic; HRSST = High-Resolution Sea Surface Temperature; PPI = plan position indicator.

from the coast (not shown) increased the data recovery percentage to $15 \%$. The overprediction was slightly smaller for this data set, but qualitatively, it did not change the patterns described above.

Although the different model simulations show similar wind speeds here, larger differences in wind speed at $100 \mathrm{~m}$ were observed downstream of the coastline on a transect located farther north (not shown). This is because of patches of different land use and roughness that were unresolved in some of the $2 \mathrm{~km}$ and USGS simulations. This shows that the similar wind speeds of different model setups at this transect are partly caused by the homogeneous terrain at the experimental site.

\subsection{Overall Model Performance}

A Taylor diagram is shown in Figure 8. The distance from the origin denotes the standard deviation. For clarity, the standard deviation of the observations is denoted with a dashed black line. The correlation coefficient is given by the radial position on the diagram, with the $x$ axis denoting a correlation coefficient of 1 , that is, a perfect agreement between observations and model. Finally, the distance to the point denoting the observations is proportional to the RMSE. The area with a dashed line is used to better distinguish the setups in Figures 9a-9c.

Most of the simulations have a RMSE around $2 \mathrm{~m} \mathrm{~s}^{-1}$ and a standard deviation around $5.5 \mathrm{~m} \mathrm{~s}^{-1}$. However, a more clear overview of the impact of changing an element of the model configuration can be achieved 


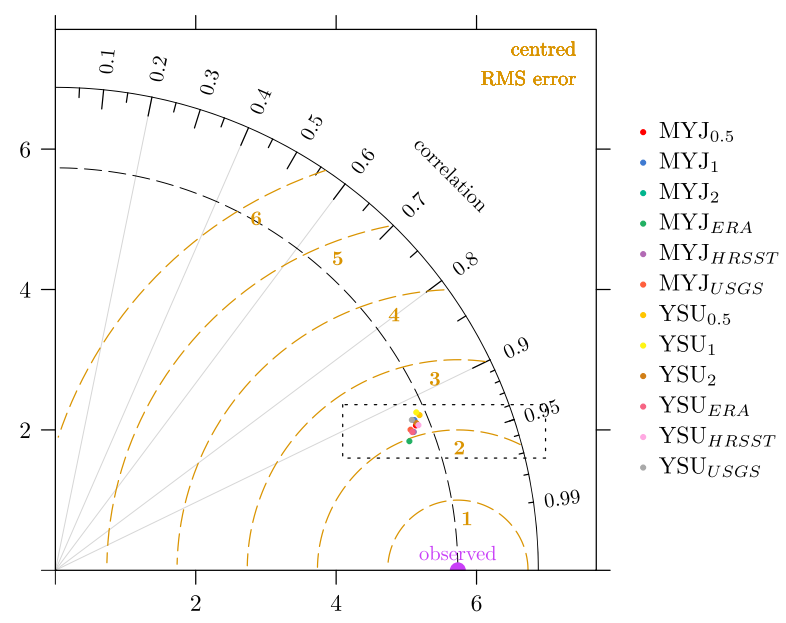

Figure 8. Taylor diagram of the model performance of the simulated wind speed in various setups during the experiment using all 401,698 ten-minute intervals from all lidars in Velocity Azimuth Display mode and the meteorological mast at all available heights. The area of the plot denoted with a dashed line is analyzed in more detail in Figure 9 to distinguish the different model setups. USGS = United States Geological Survey; YSU = Yonsei University; MYJ = Mellor-Yamada Janjic; HRSST = High-Resolution Sea Surface Temperature; by drawing an arrow from a "control" simulation to a simulation with a certain change. If the arrow points downward, it indicates that the correlation coefficient has increased and the centered RMSE has decreased, that is, a better model performance.

First, we investigate the impact of changing the PBL scheme, by drawing an arrow from those simulations that use the YSU PBL scheme to the ones using the MYJ scheme. Figure 9a shows that this change leads to a better model performance: all the arrows are pointing downward, that is, an increased correlation coefficient and decreased centered RMSE, indicating that the MYJ scheme performs better than the YSU scheme in this period. However, all arrows are pointing away from the line with the observed wind speed standard deviation, which means that the standard deviation is lower in the model simulations with the MYJ scheme than those with the YSU scheme.

One could speculate that the YSU scheme has an advantage in modeling the mostly unstable onshore flow conditions during the campaign, because of its nonlocal mixing term (Xie et al., 2012). However, the MYJ scheme has a higher-order turbulence closure. To understand the differences between the two PBL schemes, a more controlled and idealized setup is needed, which is not available for this paper.

In Figure 9b, we show the impact of changing the horizontal resolution and the SST, land, and atmospheric boundary conditions using the YSU PBL scheme. Using the ERA-Interim instead of the FNL atmospheric boundary conditions results in an improved model performance. This is not a trivial result, because the ERA-interim data not only have a much lower resolution but also have more observations assimilated in them. WRF simulations using ERA-Interim data were also found to be superior to simulations using FNL data in Carvalho et al. (2014), but they used $1^{\circ}$ resolution FNL data. Apparently, the superior data assimilation system used for creating the ERA-Interim data outweighs the fact that the FNL data have a finer grid spacing.

Increasing the horizontal grid spacing from the $2 \mathrm{~km}$ simulation results in a decreased model performance. Both the $\mathrm{YSU}_{1}$ and $\mathrm{YSU}_{0.5}$ show a lower correlation coefficient and higher centered RMSE compared to the $\mathrm{YSU}_{2}$ simulation. The simulations with higher horizontal resolution resolve more atmospheric motions: it is well known that, for example, $R$ is often penalized by increased resolution (Mass et al., 2002). A theoretical example of the decrease in the correlation coefficient that is a consequence of introducing a smaller scale wave with a known phase uncertainty is given in Kok et al. (2008). The impact of horizontal resolution is further investigated in section 4.4 .

To investigate whether the model performance changed only in the surface layer, the diagrams are split in heights below and above $80 \mathrm{~m}$ above ground level. Using USGS data instead of the CORINE land cover data results in decreased model performance below $80 \mathrm{~m}$ and above $80 \mathrm{~m}$, the difference between these simulations was negligible (not shown). Using the HR compared to the DMI SST product has a very small impact on the model performance (Figure 9c). However, it is possible that larger differences in error metrics are seen in other regions with larger differences in SST.

Figure $9 \mathrm{c}$ shows the same sensitivities as Figure $9 \mathrm{~b}$ but using the MYJ scheme. The impact of changing, for example, atmospheric or surface boundary conditions is very similar compared to that seen when the YSU scheme is used. This confirms the statistical robustness of the results and shows that the model responds similarly to different inputs of boundary conditions for the PBL schemes studied. The only exception is that the arrow from the $\mathrm{MYJ}_{0.5}$ simulation is shorter than that from the $\mathrm{YSU}_{0.5}$ simulation, indicating that using a higher resolution with the MYJ scheme does not decrease the model performance as much as when using the YSU scheme. We do not understand fully the reason for this, but this issue is further investigated in section 4.4.

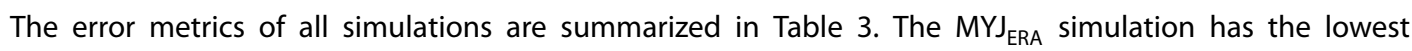
RMSE, mean absolute error, and mean bias. The mean relative errors of all simulations are generally $<1 \%$, 


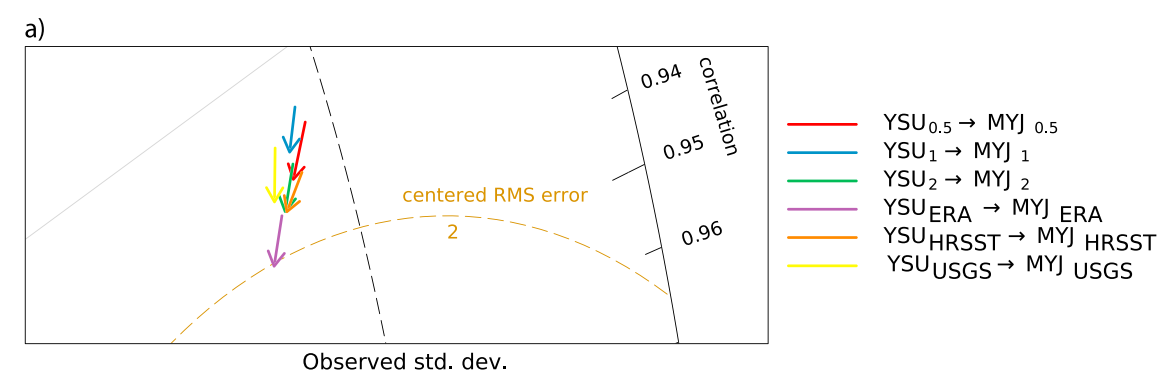

b)
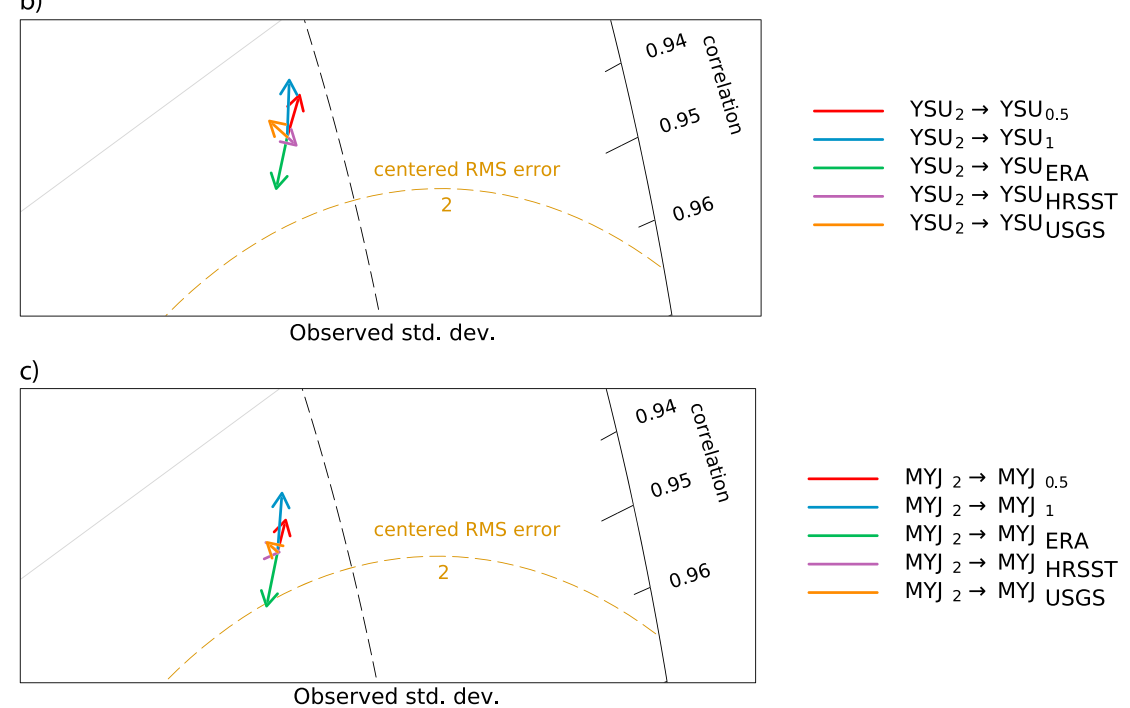

$\mathrm{YSU}_{2} \rightarrow \mathrm{YSU}_{0.5}$

$\mathrm{YSU}_{2} \rightarrow \mathrm{YSU}_{1}$

$\mathrm{YSU}_{2} \rightarrow \mathrm{YSU}_{\mathrm{ERA}}$

$\mathrm{YSU}_{2} \rightarrow$ YSU $_{\text {HRSST }}$

Observed std. dev.

Figure 9. Taylor diagrams showing the influence to the wind speed of changing the Planetary Boundary Layer scheme from Yonsei University (YSU) to Mellor-Yamada Janjic (MYJ) (a), the influence of changing the source of sea surface temperatures, horizontal resolution, reanalysis data, and land surface scheme for the MYJ scheme (b) and for the YSU scheme (c) and keeping the rest of the model configuration constant. The area depicted in each panel is shown in Figure 8. RMS = root-mean-square.

which shows that when multiple heights and locations are used for a comparison, the mesoscale model predicts the mean wind speed in this area very well. At individual sites and heights, however, there are still large errors mostly due to terrain effects not present in the WRF model (see Figures 5 and 6).

The wind direction has a positive bias compared to the observations, that is, a clockwise rotation. Because the wind in barotropic conditions is turning clockwise from the surface to the top of the boundary layer on the Northern Hemisphere, this could indicate that the cross-isobaric wind component is smaller than in the observations. The simulations using the YSU scheme have a larger bias than those using the MYJ scheme. Svensson and Holtslag (2009) showed that the angle between the surface and geostrophic wind direction modeled by different PBL schemes depends on the representation of the vertical divergence of the momentum flux close to the surface, so the smaller bias of the MYJ scheme in wind direction could indicate that it better represents the turbulent flux divergence in the PBL than the YSU scheme. The MYJ ERA $_{\text {and YSU }}$ ERA have a lower bias and a lower mean absolute error compared to the $\mathrm{MYJ}_{2}$ and $\mathrm{YSU}_{2}$ simulations, which highlights the benefits of using ERA-Interim versus FNL boundary conditions.

\subsection{Observed and Simulated Velocity Spectra}

The model setups with a higher horizontal resolution resolve a larger range of atmospheric motions. Velocity spectra have been used to investigate the representation of different scales in the atmosphere (Skamarock, 2004; Van der Hoven, 1957). To investigate the impact of increasing the resolution, we compare the spectra of the wind speed from the measurements and the model output from the simulations at the Høvsøre mast at $100 \mathrm{~m}$. The velocity spectra were not influenced by the choice of grid point. This was investigated by comparing the modeled spectra $\approx 10 \mathrm{~km}$ offshore with those inland near the Høvsøre mast; the velocity spectra at both locations were very similar. To avoid a noisy appearance in the high-frequency part of the spectrum, the observed spectra were smoothed by computing an average of a maximum of 15 Fourier coefficients in each 
Table 3

Error Metrics in Wind Speed and Direction Using 401,698 Available 10 Min Measurements From All Heights and Locations

\begin{tabular}{|c|c|c|c|c|c|c|c|c|c|}
\hline \multirow[b]{2}{*}{ Setup } & \multicolumn{7}{|c|}{ Wind speed } & \multicolumn{2}{|c|}{ Wind direction } \\
\hline & $\begin{array}{l}\text { RMSE } \\
\left(\mathrm{m} \mathrm{s}^{-1}\right)\end{array}$ & $\begin{array}{l}\text { Mean abs. } \\
\text { err. }\left(\mathrm{m} \mathrm{s}^{-1}\right)\end{array}$ & Mean bias $\left(\mathrm{m} \mathrm{s}^{-1}\right)$ & $R(-)$ & $\begin{array}{c}\text { Mean mod. } \\
\left(\mathrm{m} \mathrm{s}^{-1}\right)\end{array}$ & $\begin{array}{c}\text { Mean obs. } \\
\left(\mathrm{m} \mathrm{s}^{-1}\right)\end{array}$ & Mean rel. err. (\%) & Mean bias $\left(^{\circ}\right)$ & Mean abs. err. $\left({ }^{\circ}\right)$ \\
\hline $\mathrm{MYJ}_{0.5}$ & 2.19 & 1.57 & -0.14 & 0.92 & 12.17 & 12.31 & -1.16 & 2.34 & 11.85 \\
\hline $\mathrm{MYJ}_{1}$ & 2.26 & 1.61 & -0.15 & 0.92 & 12.17 & 12.31 & -1.19 & 2.88 & 11.89 \\
\hline $\mathrm{MYJ}_{2}$ & 2.11 & 1.52 & -0.08 & 0.93 & 12.24 & 12.31 & -0.62 & 1.37 & 11.60 \\
\hline$M Y J_{\text {ERA }}$ & 1.99 & 1.49 & -0.01 & 0.94 & 12.30 & 12.31 & -0.12 & 1.54 & 11.20 \\
\hline $\mathrm{MYJ}_{\mathrm{HRSST}}$ & 2.11 & 1.53 & -0.02 & 0.93 & 12.29 & 12.31 & -0.18 & 1.54 & 11.81 \\
\hline MYJ USGS $_{\text {US }}$ & 2.15 & 1.57 & 0.11 & 0.93 & 12.42 & 12.31 & 0.89 & 1.94 & 11.73 \\
\hline $\mathrm{YSU}_{0.5}$ & 2.32 & 1.66 & -0.09 & 0.92 & 12.23 & 12.31 & -0.70 & 3.05 & 12.06 \\
\hline $\mathrm{YSU}_{1}$ & 2.37 & 1.68 & -0.16 & 0.91 & 12.16 & 12.31 & -1.27 & 3.57 & 12.13 \\
\hline $\mathrm{YSU}_{2}$ & 2.23 & 1.58 & 0.02 & 0.92 & 12.33 & 12.31 & 0.16 & 2.65 & 11.68 \\
\hline$Y_{S U_{E R A}}$ & 2.11 & 1.55 & 0.06 & 0.93 & 12.37 & 12.31 & 0.50 & 2.36 & 11.87 \\
\hline $\mathrm{YSU}_{\mathrm{HRSST}}$ & 2.20 & 1.56 & 0.15 & 0.92 & 12.46 & 12.31 & 1.22 & 2.93 & 11.90 \\
\hline $\mathrm{YSU}_{\text {USGS }}$ & 2.29 & 1.65 & 0.20 & 0.92 & 12.51 & 12.31 & 1.60 & 2.88 & 11.85 \\
\hline
\end{tabular}

Note. The mean absolute error is defined as $\frac{1}{N} \sum_{i=1}^{N}\left|y_{i}-x_{i}\right|$, the mean bias as $\overline{y_{i}}-\overline{x_{i}}$, and the mean relative error as $100\left(\overline{y_{i}}-\overline{x_{i}}\right) / \overline{x_{i}}$. Because the wind direction error can never be more than $180^{\circ}$, the error is computed as $\left(y_{i}-x_{i}\right)\left(1-360 /\left|y_{i}-x_{i}\right|\right)$ when $\left|y_{i}-x_{i}\right|>180^{\circ}$. The best-performing simulation for each error metric is shown in bold. USGS = United States Geological Survey; YSU = Yonsei University; MYJ = Mellor-Yamada Janjic; HRSST = High-Resolution Sea Surface Temperature.

decade, whereas for the modeled spectra this number was 5. We also extracted the modeled time series from the second domain of the $\mathrm{MYJ}_{1}$ and $\mathrm{YSU}_{1}$ simulations $\left(\mathrm{MYJ}_{3}\right.$ and $\mathrm{YSU}_{3}$ ) and the third domain of the $\mathrm{MYJ}_{0.5}$ and $\mathrm{YSU}_{0.5}$ simulations $\left(\mathrm{MYJ}_{1.5}\right.$ and $\mathrm{YSU}_{1.5}$ ), to compare more horizontal grid spacings.

Larsèn et al. (2016) discussed the different frequency $(f)$ ranges of atmospheric power spectra $S(f)$ : at lower frequencies between 1 year $^{-1}<f<1$ day $^{-1}$ the slope of the spectra in the log-log scale is $\approx-3$, between 1 day $^{-1}<f<1 \mathrm{~h}^{-1}$ it is $\approx-5 / 3$, and at higher frequencies the uncertainty in the estimation of the slope is rather high and depends on the existence of a spectral gap that separates mesoscale and turbulent motions.

In Figure 10a the MYJ scheme matches well the observed spectra at frequencies larger than 1 day $^{-1}$. Between frequencies of 1 day $^{-1}$ and $1 \mathrm{~h}^{-1}$, all model simulations gradually start to underpredict the spectral density. This is caused by the numerical filters that are applied in a mesoscale model to keep a stable model solution (Skamarock, 2004). When $f<1 \mathrm{~h}^{-1}$, there are distinct differences between the simulation that result from different horizontal grid spacings: the $\mathrm{MYJ}_{0.5}$ and $\mathrm{MYJ}_{1.0}$ simulations have a much higher spectral density than the other coarser resolutions. The MYJ ${ }_{3.0}$ simulation shows a rather steep downward slope when $f<1 \mathrm{~h}^{-1}$, showing that it does not resolve these motions with this grid spacing. Therefore, a 10 min output frequency with a grid spacing of $3 \mathrm{~km}$ is unnecessary.

The simulations $\mathrm{MYJ}_{0.5}$ and $\mathrm{MYJ}_{1.0}$ have a rather different spectral slope when $f<1 \mathrm{~h}^{-1}$ compared to the simulations with higher horizontal grid spacing. Skamarock (2004) argued that such an upward turned tail in the high frequencies indicates a model that has an nonphysical treatment of these atmospheric motions. On the other hand, the observed spectral slope is similar to the modeled one for the simulations MYJ ${ }_{1.0}$ and $\mathrm{MYJ}_{1.5}$ and, for these grid spacings, it is possible that the model is capable to better represent high-frequency motions due to the higher resolution.

Note that the simulations with a grid spacing of $1 \mathrm{~km}$ have a higher spectral energy at high frequencies than those with $0.5 \mathrm{~km}$ spacing. This is likely due to the model configuration in the outer domains; the $\mathrm{MYJ}_{0.5}$ has a higher resolution near the site, but the fourth domain only covers a small area (see Figure 3 ). In domains 2 and $3, \mathrm{MYJ}_{1}$ has a higher resolution than $\mathrm{MYJ}_{0.5}$.

The velocity spectra from the simulations using the YSU scheme are shown in Figure 10b. In general, simulations with the YSU scheme have higher spectral energy than those with the MYJ scheme. Particularly, the $\mathrm{YSU}_{0.5}$ simulation has a higher spectral energy than the observations at high frequencies. 

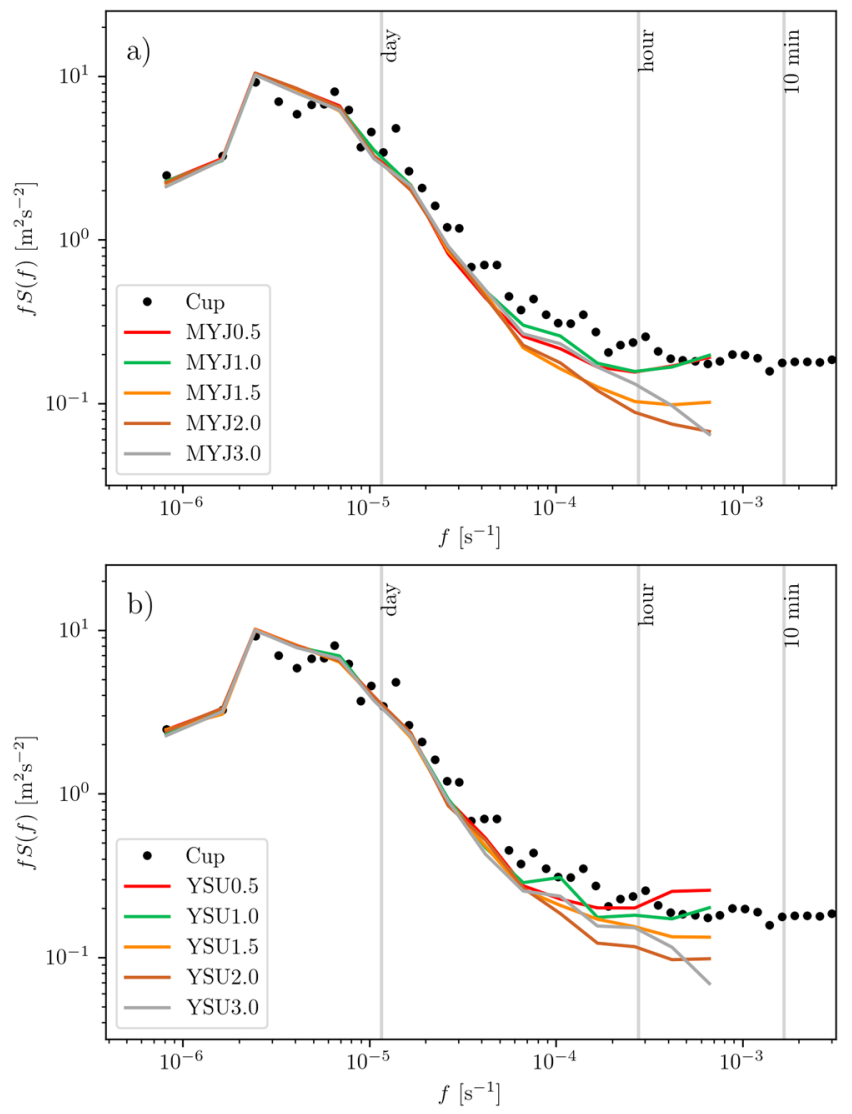

Figure 10. Velocity spectra of the model simulations at the Høvsøre mast at $100 \mathrm{~m}$ with different horizontal resolutions using the Mellor-Yamada Janjic (MYJ) (a) and the Yonsei University (YSU) scheme (b) compared to those of the observations from the cup anemometer.
This indicates that these high-resolution simulations do not realistically model high-frequency atmospheric fluctuations. This can be because $500 \mathrm{~m}$ grid spacing simulations partially resolve turbulence, especially in convective boundary layers. When a PBL scheme underestimates subgrid scale transport, it can result in too much resolved transport (Shin \& Dudhia, 2016). Honnert et al. (2011) noted that a 1.5 order boundary layer scheme in the terra incognita resolutions produced too many resolved fluctuations in a convective boundary layer, and Zhou et al. (2014) used the Rayleigh-Benard thermal instability theory and a set of idealized simulations to explain the occurrence of higher variance in the horizontal wind components.

Shin and Dudhia (2016) investigated five different PBL parametrizations in the WRF model, among which the YSU scheme, and found that none of the schemes partitioned resolved versus subgrid scale turbulence consistently when changing the grid spacing to 250,500 , and $1,000 \mathrm{~m}$ compared to large-eddy simulation data. Therefore, it appears there is currently no "best-performing" horizontal grid spacing and modeling at these fine resolutions remains rather ad-hoc. Because of the predominantly onshore winds during the evaluation period, we do not expect a large impact of the high-resolution terrain on the spectra.

The velocity spectra also partially explain the higher RMSE between model and observations of the simulations $\mathrm{YSU}_{0.5}$ and $\mathrm{MYJ}_{0.5}$. These simulations also have a higher standard deviation (see Figures $9 b$ and $9 c$ ) than the simulations with lower resolution. Therefore, investigation of velocity spectra of mesoscale model simulations provides the means to analyze how different atmospheric motion scales are represented.

\section{Summary and Discussion}

A number of mesoscale model simulations were performed to test the sensitivity of the simulated wind in the PBL to the use of different PBL schemes, atmospheric forcing, SST descriptions, land use descriptions, and horizontal grid spacing for a site along the Danish west coast. The model results were compared with observations from five vertical profiling lidars and scanning lidars at multiple heights and locations.

All mesoscale model setups were able to simulate well the mean vertical profile at different locations and the decrease of mean wind speed when moving inland was similar as observed, despite the relatively coarse resolution of some of the model simulations. The mean wind speed differences among the different setups were very small, although this is partially because of the homogeneous terrain at the experimental site. The YSU scheme had a smaller bias than the MYJ scheme at the offshore positions. The good representation of the vertical profiles at all positions indicates that mesoscale models can estimate the mean vertical wind shear at the hub height of wind turbines well, even in the complex coastal zone.

Due to the availability of scanning lidar measurements, we were for the first time able to spatially evaluate the mean horizontal wind speed gradient simulated by the mesoscale model setups. The observed mean wind speed was $\approx 0.5 \mathrm{~m} \mathrm{~s}^{-1}$ lower than simulated $\approx 5 \mathrm{~km}$ offshore. Moving inland from the coast, the mesoscale model did not represent the strong decrease in mean wind speed at $50 \mathrm{~m}$ well, probably because the microscale features of the terrain are not well resolved, both in the prescribed initial conditions and in the model itself. Increasing the horizontal resolution of the simulations did not result in a better representation of the horizontal gradient of mean wind speed.

Despite the small differences in mean wind speed among the different simulations, using Taylor diagrams revealed that there were still differences in other error metrics. Using the MYJ instead of the YSU scheme showed lower RMSEs and higher-correlation coefficients in combination with all model setups. Simulating the flow using ERA-Interim boundary conditions also led to better model predictions compared to those using FNL data. Using a horizontal grid spacing of 0.5 or 1 instead of $2 \mathrm{~km}$ resulted in a higher RMSE and lower 
correlation coefficient, which demonstrates that a finer resolution forecast is not always more skillful. Using CORINE instead of USGS land cover description improved the model skill near the surface but did not have a substantial influence higher up. Using the HR compared to the DMI SSTs only had a minor impact on the model skill.

The velocity spectra from the simulations were compared to those obtained from the high-frequency cup anemometer data. The observed and modeled spectra agreed well at the low frequencies $\left(f \approx 1\right.$ day $\left.^{-1}\right)$, but there were large differences between the simulations with different horizontal grid spacings at high frequencies $\left(f \approx 1 \mathrm{~h}^{-1}\right)$. All simulations contained less spectral energy than the observations at frequencies of $\approx 1 \mathrm{~h}^{-1}$. For the simulations with $0.5 \mathrm{~km}$ grid spacing, the tail of the spectra turned upward at high frequencies. This indicates that care should be taken (e.g., by using appropriate parametrizations and diffusion constants) when high horizontal resolutions are used in a mesoscale model. Here the computational costs of using $0.5-1 \mathrm{grid}$ spacing compared to $2 \mathrm{~km}$ are high and not needed to accurately simulate the flow in the coastal zone using the WRF model.

\section{Appendix A: Reconstruction of the Horizontal Wind Vector}

The wind vector is defined as

$$
\vec{U}=(u, v, w)
$$

where $u, v$, and $w$ are the zonal, meridional, and vertical wind speed components. We can estimate $u$ and $v$ with two scanning lidars from their LOS velocities $\left(V_{\mathrm{LOS}_{1}}\right.$ and $V_{\mathrm{LOS}_{2}}, 1$ and 2 denoting each lidar) assuming $w=0$, since

$$
\begin{aligned}
& V_{\mathrm{LOS}_{1}}=u \sin \left(\theta_{1}\right) \cos \left(\phi_{1}\right)+v \cos \left(\theta_{1}\right) \cos \left(\phi_{1}\right), \\
& V_{\mathrm{LOS}_{2}}=u \sin \left(\theta_{2}\right) \cos \left(\phi_{2}\right)+v \cos \left(\theta_{2}\right) \cos \left(\phi_{2}\right),
\end{aligned}
$$

where $\theta$ is the azimuthal angle and $\phi$ is the elevation angle. $u$ and $v$ can then be computed as

$$
\begin{aligned}
& u=\frac{V_{\mathrm{LOS}_{1}} \cos \left(\theta_{2}\right) \cos \left(\phi_{2}\right)-V_{\mathrm{LOS}_{2}} \cos \left(\theta_{1}\right) \cos \left(\phi_{1}\right)}{\cos \left(\phi_{1}\right) \cos \left(\phi_{2}\right)\left(\sin \left(\theta_{1}\right) \cos \left(\theta_{2}\right)-\sin \left(\theta_{2}\right) \cos \left(\theta_{1}\right)\right)}, \\
& v=\frac{V_{\mathrm{LOS}_{2}} \sin \left(\theta_{1}\right) \cos \left(\phi_{1}\right)-V_{\mathrm{LOS}_{1}} \sin \left(\theta_{2}\right) \cos \left(\phi_{2}\right)}{\cos \left(\phi_{1}\right) \cos \left(\phi_{2}\right)\left(\sin \left(\theta_{1}\right) \cos \left(\theta_{2}\right)-\sin \left(\theta_{2}\right) \cos \left(\theta_{1}\right)\right)} .
\end{aligned}
$$

\section{Acknowledgments}

Fundings from the ForskEL program to the project "RUNE" 12263 and the European Commission and the Energiteknologiske Udviklings- og Demonstrationsprogram (EUDP) to the "New European Wind Atlas" project through FP7 are acknowledged. We would also like to acknowledge $3 E$ for adding the $3 E$ lidar to RUNE's network, Fraunhofer IWES for the measurements from the lidar buoy, and the technicians of DTU Wind Energy, Fraunhofer IWES and the Danish Hydrological Institute for their work and support during the campaign. The data used in this paper are available for download (Floors et al., 2017).

\section{References}

Anderson, J. R., Harde, E. E., Roach, J. T., \& Witmer, R. E. (1976). A land use and land cover classification system for use with remote sensor data (Vol. 964, 27 pp.). Washington: US Government Printing Office.

Banta, R. M., Newsom, R. K., Lundquist, J. K., Pichugina, Y. L., Mahrt, L., \& Coulter, R. L. (2001). Nocturnal low-level jet characteristics over Kansas during cases-99. Boundary-Layer Meteorology, 105(2), 221-252. https://doi.org/10.1023/A:1019992330866

Barthelmie, R., Badger, J., Pryor, S., Hasager, C., Christiansen, M., \& Jørgensen, B. (2007). Offshore coastal wind speed gradients: Issues for the design and development of large offshore windfarms. Wind Engineering, 31(6), 369-382. https://doi.org/10.1260/030952407784079762

Bingö, F., Mann, J., \& Foussekis, D. (2009). Conically scanning lidar error in complex terrain. Meteorologische Zeitschrift, 18(2), $189-195$. https://doi.org/10.1127/0941-2948/2009/0368

Carvalho, D., Rocha, A., Gómez-Gesteira, M., \& Silva Santos, C. (2014). WRF wind simulation and wind energy production estimates forced by different reanalyses: Comparison with observed data for Portugal. Applied Energy, 117, 116-126. https://doi.org/10.1016/ j.apenergy.2013.12.001

Cohen, A. E., Cavallo, S. M., Coniglio, M. C., \& Brooks, H. E. (2015). A review of planetary boundary layer parameterization schemes and their sensitivity in simulating southeastern U.S. cold season severe weather environments. Weather and Forecasting, 30(3), $591-612$. https://doi.org/10.1175/WAF-D-14-00105. 1

Dee, D. P., Uppala, S. M., Simmons, A. J., Berrisford, P., Poli, P., Kobayashi, S., et al. (2011). The ERA-Interim reanalysis: Configuration and performance of the data assimilation system. Quarterly Journal of the Royal Meteorological Society, 137(656), 553-597. https://doi.org/10.1002/qj.828

Dörenkämper, M., Optis, M., Monahan, A., \& Steinfeld, G. (2015). On the offshore advection of boundary-layer structures and the influence on offshore wind conditions. Boundary-Layer Meteorology, 155(3), 459-482. https://doi.org/10.1007/s10546-015-0008-x

Dvorak, M. J., Archer, C. L., \& Jacobson, M. Z. (2009). California offshore wind energy potential. Renewable energy, 35, 1244-1254. https://doi.org/10.1016/j.renene.2009.11.022

Floors, R., Hahmann, A. N., \& Peña, A. (2017). Files with RUNE experiment measurements and WRF modelling results. https://doi.org/10.5281/zenodo.1137715 
Floors, R., Peña, A., Lea, G., Vasiljević, N., Simon, E., \& Courtney, M. (2016). The RUNE experiment-A database of remote-sensing observations of near-shore winds. Remote Sensing, 8(11), 884. https://doi.org/10.3390/rs8110884

Floors, R., Vincent, C. L., Gryning, S.-E., Peña, A., \& Batchvarova, E. (2013). The wind profile in the coastal boundary layer: Wind lidar measurements and numerical modelling. Boundary-Layer Meteorology, 147(3), 469-491. https://doi.org/10.1007/s10546-012-9791-9

Frank, H. P., Rathmann, O., Mortensen, N. G., \& Landberg, L. (2001). The numerical Wind Atlas. The KAMM/WAsP method. In Conference proceedings (on CD-ROM). Washington, DC: American Wind Energy Association (AWEA).

Garratt, J. R. (1990). The internal boundary layer-A review. Boundary-Layer Meteorology, 50(1-4), 171-203. https://doi.org/10.1007/BF00120524

Gemmill, W., Katz, B., \& Li, X. (2007). Daily real-time global sea surface temperature — High resolution analysis at NOAA/NCEP (Tech. Rep.). NCEP/NOAA, Camp Springs.

Gottschall, J., \& Courtney, M. (2010). Verification test for three WindCube WLS7 LiDARs at the Høvsøre test site.

Gryning, S.-E., Floors, R., Peña, A., Batchvarova, E., \& Brümmer, B. (2016). Weibull wind-speed distribution parameters derived from a combination of wind-lidar and tall-mast measurements over land, coastal and marine sites. Boundary-Layer Meteorology, 159(2), 329-348. https://doi.org/10.1007/s10546-015-0113-x

Hahmann, A. N., Vincent, C. L., Peña, A., Lange, J., \& Hasager, C. B. (2015). Wind climate estimation using WRF model output: Method and model sensitivities over the sea. International Journal of Climatology, 35(12), 3422-3439. https://doi.org/10.1002/joc.4217

Hall, F. F., Huffaker, R. M., Hardesty, R. M., Jackson, M. E., Lawrence, T. R., Post, M. J., et al. (1984). Wind measurement accuracy of the NOAA pulsed infrared Doppler lidar. Applied Optics, 23(15), 2503-2506. https://doi.org/10.1364/AO.23.002503

Hill, M., Calhoun, R., Fernando, H. J. S., Wieser, A., Dörnbrack, A., Weissmann, M., et al. (2010). Coplanar Doppler lidar retrieval of rotors from T-REX. Journal of the Atmospheric Sciences, 67(3), 713-729. https://doi.org/10.1175/2009JAS3016.1

Honnert, R., Masson, V., \& Couvreux, F. (2011). A diagnostic for evaluating the representation of turbulence in atmospheric models at the kilometric scale. Journal of the Atmospheric Sciences, 68(12), 3112-3131. https://doi.org/10.1175/JAS-D-11-061.1

Høyer, J. L., \& Karagali, I. (2016). Sea surface temperature climate data record for the North Sea and Baltic Sea. Journal of Climate, 29(7), 2529-2541. https://doi.org/10.1175/JCLI-D-15-0663.1

Hunt, J., Orr, A., Rottman, J., \& Capon, R. (2004). Coriolis effects in mesoscale flows with sharp changes in surface conditions. Quarterly Journal of the Royal Meteorological Society, 130(603), 2703-2731. https://doi.org/10.1256/qj.04.14

Janjić, Z. I. (1990). The step-mountain coordinate: Physical package. Monthly Weather Review, 118(7), 1429-1443. https://doi.org/10.1175/1520-0493(1990)118<1429:TSMCPP >2.0.CO;2

Kok, K., Schreur, B. W., \& Vogelezang, D. (2008). Valuing information from mesoscale forecasts. Meteorological Applications, $15(1), 103-111$. https://doi.org/10.1002/met.54

Lange, B., Larsen, S., Højstrup, J., \& Barthelmie, R. (2004). Importance of thermal effects and sea surface roughness for offshore wind resource assessment. Journal of Wind Engineering and Industrial Aerodynamics, 92(11), 959-988. https://doi.org/10.1016/ j.jweia.2004.05.005

Larsèn, X. G., Larsen, S. E., \& Petersen, E. L. (2016). Full-scale spectrum of boundary-layer winds. Boundary-Layer Meteorology, 159(2), 349-371. https://doi.org/10.1007/s10546-016-0129-x

Mass, C. F., Ovens, D., Westrick, K., \& Colle, B. A. (2002). Does increasing horizontal resolution produce more skillful forecasts? Bulletin of the American Meteorological Society, 83(3), 407-430. https://doi.org/10.1175/1520-0477(2002)083<0407:DIHRPM>2.3.CO;2

Mellor, G. L., Yamada, T., \& Alarnos, L. (1982). Development of a turbulence closure model for geophysical fluid problems. Reviews of Geophysics, 20(4), 851. https://doi.org/10.1029/RG020i004p00851

Mikkelsen, T. (2014). Lidar-based research and innovation at DTU Wind Energy-A review. Journal of Physics: Conference Series, 524(1), 12007. https://doi.org/10.1088/1742-6596/524/1/012007

National Centers for Environmental Prediction/National Weather Service/NOAA/U.S. Department of Commerce (2015). NCEP GDAS/FNL 0.25 Degree Global Tropospheric Analyses and Forecast Grids. Research Data Archive at the National Center for Atmospheric Research, Computational and Information Systems Laboratory. https://doi.org/10.5065/D65Q4T4Z (Accessed 1 November 2015)

Newsom, R., Calhoun, R., Ligon, D., \& Allwine, J. (2008). Linearly organized turbulence structures observed over a suburban area by dual-Doppler lidar. Boundary-Layer Meteorology, 127(1), 111-130. https://doi.org/10.1007/s10546-007-9243-0

Nielsen, J. R. (2013). Representing vegetation processes in hydro-meteorological simulations using the WRF model (Phd thesis, Riso-PhD-0016(EN)). Roskilde, Denmark: Riso National Laboratory for Sustainable Energy, Technical University of Denmark.

Noh, Y., Cheon, W. G., \& Hong, S. Y. (2003). Improvement of the K-profile model for the planetary boundary layer based on large Eddy simulation data. Boundary-Layer Meteorology, 107(2), 401-427. https://doi.org/10.1023/A: 1022146015946

Nunalee, C. G., \& Basu, S. (2014). Mesoscale modeling of coastal low-level jets: Implications for offshore wind resource estimation. Wind Energy, 17(8), 1199-1216. https://doi.org/10.1002/we.1628

Olsen, B. T., Hahmann, A. N., Sempreviva, A. M., Badger, J., \& Jørgensen, H. E. (2017). An intercomparison of mesoscale models at simple sites for wind energy applications. Wind Energy Science, 2(1), 211-228. https://doi.org/10.5194/wes-2-211-2017

Peña, A., Floors, R., Sathe, A., Gryning, S.-E., Wagner, R., Courtney, M. S., et al. (2016). Ten years of boundary-layer and wind-power meteorology at Høvsøre, Denmark. Boundary-Layer Meteorology, 158(1), 1-26. https://doi.org/10.1007/s10546-015-0079-8

Pindea, N., Jorba, O., Jorge, J., \& Baldasano, J. M. (2002). Using NOAA AVHRR and SPOT VGT data to estimate surface parameters: Application to a mesoscale meteorological model. International Journal of Remote Sensing, 1161, $129-143$. https://doi.org/10.1080/0143116031000115201

Radu, R., Déqué, M., \& Somot, S. (2008). Spectral nudging in a spectral regional climate model. Tellus A: Dynamic Meteorology and Oceanography, 60(5), 898-910. https://doi.org/10.1111/j.1600-0870.2008.00341.x

Shin, H. H., \& Dudhia, J. (2016). Evaluation of PBL parameterizations in WRF at subkilometer grid spacings: Turbulence statistics in the dry convective boundary layer. Monthly Weather Review, 144(3), 1161-1177. https://doi.org/10.1175/MWR-D-15-0208.1

Skamarock, W. C. (2004). Evaluating mesoscale NWP models using kinetic energy spectra. Monthly Weather Review, 132(12), 3019-3032. https://doi.org/10.1175/MWR2830.1

Skamarock, W. C., Klemp, J. B., Dudhia, J., Gill, D. O., Barker, D. M., Duda, M. G., et al. (2008). A description of the Advanced Research WRF version 3 (Tech. Rep., NCAR/TN-475+ STR, 113 pp.). Boulder: Mesoscale and Microscale Meteorology Division, National Center for Atmospheric Research.

Svensson, G., \& Holtslag, A. A. M. (2009). Analysis of model results for the turning of the wind and related momentum fluxes in the stable boundary layer. Boundary-Layer Meteorology, 132(2), 261-277. https://doi.org/10.1007/s10546-009-9395-1

Tammelin, B., Vihma, T., Atlaskin, E., Badger, J., Fortelius, C., Gregow, H., et al. (2013). Production of the Finnish Wind Atlas. Wind Energy, 16(1), 19-35. https://doi.org/10.1002/we.517 
Taylor, K. E. (2001). Summarizing multiple aspects of model performance in a single diagram. Journal of Geophysical Research, 106(D7), 7183-7192. https://doi.org/10.1029/2000JD900719

Troen, I. B., \& Mahrt, L. (1986). A simple model of the atmospheric boundary layer; sensitivity to surface evaporation. Boundary-Layer Meteorology, 37(1-2), 129-148. https://doi.org/10.1007/BF00122760

Van der Hoven, I. (1957). Power spectrum of horizontal wind speed in the frequency range from 0.0007 to 900 cycles per hour. Journal of Applied Meteorology, 14(2), 160-164. https://doi.org/10.1175/1520-0469(1957)014<0160:PSOHWS>2.0.CO;2

Vasiljević, N., \& Courtney, M. (2017). Accuracy of dual-Doppler lidar retrievals of near-shore winds. In WindEurope Resource Assessment Workshop, Edinburgh, United Kingdom. 16/03/2017, http://orbit.dtu.dk/files/131412313/Submitted_Vasiljevic.pptx

Vasiljević, N., Lea, G., Courtney, M., Cariou, J.-P., Mann, J., \& Mikkelsen, T. (2016). Long-range WindScanner system. Remote Sensing, 8(12), 896. https://doi.org/10.3390/rs8110896

Vincent, C. L., \& Hahmann, A. N. (2015). The impact of grid and spectral nudging on the variance of the near-surface wind speed. Journal of Applied Meteorology and Climatology, 54(5), 1021-1038. https://doi.org/10.1175/JAMC-D-14-0047.1

Wijnant, I. L., Van Den Brink, H., \& Stepek, A. (2014). North Sea wind climatology part 2: ERA-Interim and Harmonie model data (Tech Rep.). De Bilt: KNMI.

Wyngaard, J. C. (2004). Toward numerical modeling in the "terra incognita". Journal of the Atmospheric Sciences, 61(14), $1816-1826$. https://doi.org/10.1175/1520-0469(2004)061<1816:TNMITT>2.0. CO;2

Xie, B., Fung, J. C.-H., Chan, A., \& Lau, A. K.-H. (2012). Evaluation of nonlocal and local planetary boundary layer schemes in the WRF model. Journal of Geophysical Research, 117, D12103. https://doi.org/10.1029/2011JD017080

Zhou, B., Simon, J. S., Chow, F. K., Zhou, B., Simon, J. S., \& Chow, F. K. (2014). The convective boundary layer in the terra incognita. Journal of the Atmospheric Sciences, 71(7), 2545-2563. https://doi.org/10.1175/JAS-D-13-0356.1 